\title{
Spatial and Temporal Variability of Sediment Organic Matter Recycling in Two Temperate Eutrophicated Estuaries
}

\author{
Karima Khaliil, ${ }^{1,}$, Mélanie Raimonet ${ }^{2}$, Anniet M. Laverman ${ }^{2}$, Chen Yan $^{2}$, Françoise Andrieux-Loyer ${ }^{3}$, \\ Eric Viollier ${ }^{4}$, Bruno Deflandre $^{5}$, Olivier Ragueneau ${ }^{6}$, Christophe Rabouille $^{7}$
}

\footnotetext{
1 Ecole Supérieure de Technologie d'Essaouira, Université Cadi Ayyad, Km 9, Route d'Agadir, BP. 383, Essaouira, Aljadida, Marocco

${ }^{2}$ UMR 7619 Sisyphe, Université Pierre et Marie Curie/CNRS, 4 place Jussieu, 75252, Paris Cedex 05, France

${ }^{3}$ Département Dyneco Pelagos, Centre de Bres, IFREMER, Plouzané, France

4 Sorbonne Paris Cité, Institut de Physique du Globe de Paris, UMR 7154 CNRS, Univ. Paris Diderot, 75013, Paris, France

5 OASU UMR 5805 EPOC, Université de Bordeaux 1, avenue des facultés, 33405, Talence, France

${ }^{6}$ UMR CNRS 6539, Technopôle Brest-Iroise, Institut Universitaire Européen de la Mer, Place Nicolas Copernic, 29280 , Plouzané, France

${ }^{7}$ Laboratoire des Sciences du Climat et de l'Environnement, Laboratoire mixte CNRS-CEA, Av. de la Terrasse, 91190, Gif sur Yvette, France

*: Corresponding author : Karima Khalil, email address : ka.khalil@uca.ma
}

\begin{abstract}
:
This paper deals with the spatial and seasonal recycling of organic matter in sediments of two temperate small estuaries (Elorn and Aulne, France). The spatio-temporal distribution of oxygen, nutrient and metal concentrations as well as the organic carbon and nitrogen contents in surficial sediments were determined and diffusive oxygen fluxes were calculated. In order to assess the source of organic carbon $(\mathrm{OC})$ in the two estuaries, the isotopic composition of carbon $\left(\delta^{13} \mathrm{C}\right)$ was also measured. The temporal variation of organic matter recycling was studied during four seasons in order to understand the driving forces of sediment mineralization and storage in these temperate estuaries. Low spatial variability of vertical profiles of oxygen, nutrient, and metal concentrations and diffusive oxygen fluxes were monitored at the station scale (within meters of the exact location) and crosssection scale. We observed diffusive oxygen fluxes around $15 \mathrm{mmol} \mathrm{m}^{-2}$ day $^{-1}$ in the Elorn estuary and $10 \mathrm{mmol} \mathrm{m}^{-2}$ day $^{-1}$ in the Aulne estuary. The outer (marine) stations of the two estuaries displayed similar diffusive $\mathrm{O}_{2}$ fluxes. Suboxic and anoxic mineralization was large in the sediments from the two estuaries as shown by the rapid removal of very high bottom water concentrations of NO $x^{-}(>200 \mu \mathrm{M})$ and the large $\mathrm{NH}_{4}{ }^{+}$increase at depth at all stations. OC contents and $\mathrm{C} / \mathrm{N}$ ratios were high in upstream sediments (11-15\% d.w. and 4-6, respectively) and decreased downstream to values around $2 \%$ d.w. and $\mathrm{C} / \mathrm{N} \leq 10 . \delta^{13} \mathrm{C}$ values show that the organic matter has different origins in the two watersheds as exemplified by lower $\delta{ }^{13} \mathrm{C}$ values in the Aulne watershed. A high increase of $\delta{ }^{13} \mathrm{C}$ and $\mathrm{C} / \mathrm{N}$ values was visible in the two estuaries from upstream to downstream indicating a progressive mixing of terrestrial with marine organic matter. The Elorn estuary is influenced by human activities in its watershed (urban area, animal farming) which suggest the input of labile organic matter, whereas the Aulne estuary displays larger river primary production which can be either mineralized in the water column or transferred to the lower estuary, thus leaving a lower mineralization in Aulne than
\end{abstract}


the water column or transferred to the lower estuary, thus leaving a lower mineralization in Aulne than Elorn estuary. This study highlights that (1) meter scale heterogeneity of benthic biogeochemical properties can be low in small and linear macrotidal estuaries, (2) two estuaries that are geographically close can show different pattern of organic matter origin and recycling related to human activities on watersheds, (3) small estuaries can have an important role in recycling and retention of organic matter.

\section{Introduction}

This paper pays tribute to the vast work of Fred Mackenzie who has been a pioneer and a continuous contributor to the quantification of fluxes between the continent and the ocean. In the spirit of Fred's vision which goes from local investigation of processes to the global scale quantification, this paper deals with local 
observations of two specific estuaries on a seasonal basis linked to generalized retention and alteration processes of carbon and nitrogen during its transfer between the continent and the coastal zone.

Estuaries are important filters for both dissolved and particulate components originating from land (Bopp et al. 1982; Nixon et al. 1996; Rabouille et al. 2001; Cloern and Jassby 2012 and references therein), which are ultimately transferred to the coastal sea. A variable proportion of nutrients is consumed by primary production and heterotrophic microbial activity (Cloern 1996), whereas dissolved and particulate carbon is recycled in estuaries (Raymond and Bauer 2001) leading to heterotrophic estuaries representing a net source of $\mathrm{CO}_{2}$ to the atmosphere (Borges 2005). As a consequence, the organic matter deposited in estuarine sediments originates from autochtonous as well as allochtonous sources (terrestrial, marine) (Cifuentes et al. 1988). Estuarine sediments are important environments regulating carbon, nutrient, metal and sulfur fluxes. The top layers of these sediments are known for their high biogeochemical activity due to organic matter mineralization by a consortium of bacteria using different electron acceptors (oxygen, nitrate, metal oxides, sulfate). Oxygen $\left(\mathrm{O}_{2}\right)$ plays an important role in the turnover of organic matter in sediments (Glud 2008) and in the re-oxidation of reduced compounds originating from anoxic mineralization, diffusing up to the oxic zone from deeper layers (Canfield et al. 1993; Deflandre et al. 2002; Pastor et al. 2011a). Denitrification and alternative nitrate removal pathways (Seitzinger 1998; Burgin and Hamilton 2007) that occur in marine and estuarine sediments are also very important in regulating fixed nitrogen fluxes to the coastal zone. Finally, sulfate reduction and methanogenesis are major processes of organic matter degradation in shallow water sediments, which contribute to the overall mineralization of organic carbon and may contribute to the reduction of carbon inputs to the coastal sea (e.g. Middelburg, et al. 1995; Meiggs and Taillefert 2011).

The Elorn and Aulne estuaries are two temperate small estuaries located in Northwestern France. Intense agricultural activity in the watersheds has led to high riverine nitrate inputs, which recurrently lead to green algal blooms downstream of the Elorn Estuary. In spite of these local symptoms, the macrotidal Bay of Brest resists to major eutrophication due to the intense mixing with oceanic waters and to the presence of an invasive benthic filter feeder (Le Pape et al. 1996; Ragueneau et al. 2002; Laruelle et al. 2009). Even if the two estuaries are geographically close, they are characterized by different morphology and by different estuarine and watershed characteristics, which potentially control organic matter quality and recycling together with nutrient fate in the estuary.

The aim of this study is to determine the spatial and temporal variability of carbon, oxygen and nutrient dynamics in sediments of these two small temperate and macrotidal estuaries in order to evaluate the retention 
and transformation capacity. The originality of this study is to evaluate the variability of retention and transformation capacity in temperate estuaries that are geographically close, and to link the differences observed with their properties. Therefore, we examined the spatio-temporal distribution of benthic oxygen, pore water nutrients and metals $\left(\mathrm{NO}_{\mathrm{x}}{ }^{-}, \mathrm{NH}_{4}{ }^{+}, \mathrm{Fe}^{2+}, \mathrm{Mn}^{2+}, \mathrm{SO}_{4}{ }^{2-}\right.$ and $\left.\mathrm{H}_{2} \mathrm{~S}\right)$ along the salinity gradients during four seasons. In addition, we compared small scale heterogeneity of in-situ oxygen microprofiles and porewater profiles to variations at the estuarine scale. Furthermore, the source of the organic carbon in the two estuaries was assessed by its isotopic composition. Finally, we explored the effect of different environmental parameters, such as in-situ temperature, salinity, bottom water oxygenation, organic matter input on the organic matter cycling in these estuarine sediments.

\section{Materials and methods}

\subsection{Study sites}

The Elorn and Aulne estuaries are located at the interface between the rivers and the semi-enclosed Bay of Brest in Northwestern France (Fig.1). Riverine waters entering these shallow estuaries are particularly rich in nutrients, essentially nitrate, in response to intensive agriculture in the watersheds (Del Amo 1996; Ragueneau et al. 2002). Although the Elorn watershed is 8 times smaller than the Aulne watershed ( 280 versus $1822 \mathrm{~km}^{2}$ ), this system is impacted by a higher population (285000 versus 70000 habitants). By its location in Northwerstern France, the whole domain is exposed to an oceanic climate. High precipitation associated to frequent storms are thus observed during winter, which lead to seasonal fluctuations of river discharge from winter (42 and $189 \mathrm{~m}^{3} \mathrm{~s}^{-}$ 1 in 2009) to summer (1.0 and $1.7 \mathrm{~m}^{3} \mathrm{~s}^{-1}$ in 2009) in Elorn and Aulne rivers (Banque HYDRO, http://www.hydro.eaufrance.fr). Even if exposed to similar climate by their proximity, the two estuaries differ by their morphology. While the Elorn Estuary is shorter ( $\sim 15 \mathrm{~km})$, straight and more directly exposed to marine hydrodynamic influence, the Aulne estuary is longer ( $35 \mathrm{~km}$ ), meandering and more protected by the Bay of Brest.

\subsection{Field sampling}

Sediment core samples were collected along the Elorn and Aulne estuaries during four cruises in February, May, July and October/November 2009. Sampling was undertaken in the inner (stations E1 and A1), mid (stations E2 and A2) and outer (stations E3 and A3) Elorn and Aulne estuaries (Fig.1). Samples were 
collected in subtidal shores - between the channel and the border - at mid-tide. Each station was sampled a different day to collect all samples at mid tide. Sediment cores were additionally sampled along the transversal section in the mid Elorn Estuary. The stations (named E2, b, c, d and e) were homogeneously spaced from the left to the right side of the cross-section (75 m width; Fig.1). Sediment cores were sampled from a semi-rigid boat with a gravity corer (UWITEC ${ }^{\circledR}$ ) equipped with Plexiglas tubes (8.6- $\mathrm{cm}$ internal diameter x 60 -cm long). Corer weight allowed 25-45 cm penetration into the sediment without disturbing the sediment-water interface. Sampling was performed on board the N/O Côtes de la Manche anchored at a fixed position. A total of 5 sediment cores were simultaneously sampled at each station: 1 core for oxygen profile measurements $(n>3)$, 3 cores for porosity, nutrient and metal concentrations in pore waters $(n=3)$, and 1 core for salinity, sulfate and sulfide concentrations in pore waters $(\mathrm{n}=1)$. Bottom water samples were taken with a Niskin bottle for oxygen measurement. The transfer of water from the Niskin bottle to the three Winkler bottles was carefully performed avoiding water bubbles. Reagents were immediately added and bottles were closed. Temperature and salinity of overlying waters were recorded immediately after sampling and core were capped and brought back to the main research ship (maximum 1 hour).

\subsection{Solid-phase analyses}

Triplicate sediment cores were immediately sliced at $0.5 \mathrm{~cm}$ intervals in the first $2 \mathrm{~cm}$, at $1 \mathrm{~cm}$ intervals for 2-4 cm, at $2 \mathrm{~cm}$ intervals for $4-12 \mathrm{~cm}$, and at $4 \mathrm{~cm}$ intervals for $12-20 \mathrm{~cm}$. An aliquot of the sediment was placed in a vial for porosity measurements. Sediment porosity was determined by drying wet sediment of precise volume at $60^{\circ} \mathrm{C}$ for 5 days and determining the loss of weight (Berner 1980).

The total nitrogen and organic carbon contents were measured in surficial sediments collected in February, May, July and October 2009 for all stations. In February 2009, the 0-0.5 cm depth was measured for all stations, and additionnal the 2-3, 8-10 and 16-20 cm depths were analyzed in intermediate estuaries. As the composition of the upper sediment layer was very homogeneous down to $3 \mathrm{~cm}$, a 50/50 mix of the 0-0.5 and 2-3 cm depth was analyzed for all other cruises. We used an automatic Carlo Erba NA1500 analyser, after removal of the carbonate fraction by dissolution in $\mathrm{HCl} 1.2 \mathrm{~N}$. Organic carbon and total nitrogen concentrations were expressed as the percentage of sediment dry weight (\% d.w.). The average standard deviation of each measurement, determined by replicate analyses of the same sample, was $\pm 0.05 \%$ d.w. for total nitrogen (TN) and $\pm 0.03 \%$ d.w. for organic carbon (OC). Stable isotopic composition of the sedimentary organic carbon $\left(\delta^{13} \mathrm{C}\right)$ was determined with continuous flow FINNIGAN Delta plus XP mass spectrometer, which was directly coupled to the CHN analyser 
(Gauthier and Hatté 2007). $\delta^{13} \mathrm{C}$ values were expressed as the relative difference between isotopic ratios in the sample and in conventional standards (Vienna Pee Dee Belemnite) .

$$
\delta^{13} C=\left[\frac{\left({ }^{13} C /{ }^{12} C\right) \text { sample }}{\left({ }^{13} C /{ }^{12} C\right) P D B}-1\right] \times 1000
$$

Isotopic results were obtained with uncertainties of $\pm 0.2 \%$ as determined from routine replicate measurements.

\subsection{Oxygen profiles}

On board the ship, sediment cores were immediately placed in a refrigerating loop with a monitoring of temperature and brought back to their initial temperature while bubbled with air. The maximum temperature difference between sampling and ship recovery was $<2^{\circ} \mathrm{C}$. The efficiency of the refrigerating loop was increased by the circulation of the overlying water into a cold bath, which brought this water back to the sampling temperature within 1 hour. Oxygen profiles in pore waters were performed on board using Clark type polarographic oxygen microsensors provided with a built-in reference and an internal guard cathode (Revsbech 1989). The sensors have an outer tip diameter of $50 \mu \mathrm{m}$ and were manufactured by Unisense (Århus, DK). The sensors were operated with a motor-driven micromanipulator and the sensor current was measured with a picoamperometer connected to an A-D converter, which transferred the signals to a PC (Revsbech and Jørgensen 1986). At each site, a minimum of 3 oxygen profiles was performed in the same core. Linear calibration of microelectrodes was achieved between bottom water oxygenation estimated by Winkler titration (Grasshoff et al. 1983) and anoxic (i.e. oxygen-free) sediments. The vertical resolution of measurements was 100-200 $\mu \mathrm{m}$. The position of the sediment-water interface (SWI) relative to the in-situ oxygen profiles was determined using a modified version of the technique of Sweerts and De Beer (1989) which defined the SWI as the first point in the oxygen gradient, after the initial linear oxygen decrease in the diffusive boundary layer, with a slope increase of more than $20 \%$.

\subsection{Pore water analyses}

Sediment aliquots for nutrient, metals and salinity analyses were placed in sealed $50 \mathrm{ml}$ centrifuge tubes containing Vectaspin 20 filters $\left(0.45 \mu \mathrm{m}\right.$ pore size, Whatman $\left.^{\circledR}\right)$ according to Andrieux-Loyer et al. (2008). Pore water was extracted by centrifuging at $3075 \mathrm{~g}$ for 10 min ( 2 times) at $4^{\circ} \mathrm{C}$ and acidified to $\mathrm{pH} 2$ for further nutrient $\left(\mathrm{NO}_{\mathrm{x}}{ }^{-}\right.$and $\left.\mathrm{NH}_{4}{ }^{+}\right)$and metal $\left(\mathrm{Fe}^{2+}, \mathrm{Mn}^{2+}\right)$ analyses. $\mathrm{NO}_{\mathrm{x}}{ }^{-}$and $\mathrm{NH}_{4}{ }^{+}$concentrations were analyzed using segmented flow analysis (SFA; Aminot et al. 2009). $\mathrm{Fe}^{2+}$ concentrations were measured with the ferrozine 
method (Sarradin et al. 2005) and $\mathrm{Mn}^{2+}$ concentrations with the leuco-malachite green method (Resing and Mottl 1992), both adapted for SFA. The precision of the analysis was $0.5 \%$.

One additional core per site was equipped with Rhizons and polypropylene syringes (Seeberg-Elverfeldt et al. 2005), allowing sampling of the pore water at different depth intervals. The Rhizons were placed at $1 \mathrm{~cm}$ intervals. The pore water collected at the different depths was kept at $4^{\circ} \mathrm{C}$ until analysis. An aliquot of the sample $(200 \mu \mathrm{l})$ was distributed in pre-acidified tubes ( $\mathrm{HCl}$ normapur, $10^{-2} \mathrm{M}$ ) for sulfate analysis. $\mathrm{BaCl}_{2}$ plus gelatin reagent was added to precipitate barium sulfate and maintain barite precipitate in suspension. Turbidity was recorded at $470 \mathrm{~nm}$ (Tabatabai 1974). A sample fraction for $\mathrm{LH}_{2} \mathrm{~S}$ analysis (200 $\mu \mathrm{l}$ ) was immediately transferred to a tube containing $3 \mathrm{ml}$ of a trap solution consisting of zinc chloride $\left(1.5 \times 10^{-2} \mathrm{M}\right)$ and gelatin $\left(3 \mathrm{~g} \mathrm{l^{-1 }}\right)$ to precipitate ZnS (preventing sulfide oxidation and gas loss). When necessary, samples were diluted with $\mathrm{NaCl}$ stock solution whose composition matched surface seawater salinity. Total hydrogen sulfide concentrations were measured by the methylene blue method (Merck Spectroquant ${ }^{\circledR} 14779 ; \lambda=660 \mathrm{~nm}$ ). Standards were prepared with a daily made $\mathrm{Na}_{2} \mathrm{~S}$ stock solution $(\sim 10 \mathrm{mM})$. Salinity was measured by conductivity against a $\mathrm{S}=35 \mathrm{OSIL}$ standard.

\subsection{Diffusive oxygen flux calculations}

Diffusive oxygen uptake (DOU) was calculated from $\mathrm{O}_{2}$ concentration gradients at the sediment-water interface by using the 1-D Fick's first law of diffusion: DOU $=\varphi \mathrm{D}_{\mathrm{s}}\left[\frac{\mathrm{dO} \mathrm{O}_{2}}{\mathrm{~d} x}\right]_{x=0}$ where $\varphi$ is the porosity, $\mathrm{D}_{\mathrm{s}}$ is the $\mathrm{O}_{2}$ diffusion coefficient within the sediment and $\left[\frac{\mathrm{dO}}{\mathrm{d} x}\right]_{x=0}$ is the oxygen gradient just below the sedimentwater interface (estimated from the profiles). $\mathrm{D}_{\mathrm{s}}$ was estimated as $\mathrm{D}_{\mathrm{s}}=\frac{\mathrm{D}_{\mathrm{O}_{\mathrm{O}_{2}}}}{\varphi_{2}} \cdot \mathrm{D}_{0_{\mathrm{O}_{2}}}$ is the molecular diffusion coefficient of $\mathrm{O}_{2}\left(\mathrm{~cm}^{2} \mathrm{~s}^{-1}\right)$ at in situ temperature, salinity and hydrostatic pressure and was evaluated using tables from Broecker and Peng (1974). The oxygen gradient was estimated over 400 to 600 microns depending on the resolution of the profiles.

In order to establish a seasonal comparison of fluxes without temperature effect, $\mathrm{O}_{2}$ fluxes obtained previously at in situ temperature were all recalculated for a standard temperature of $10^{\circ} \mathrm{C}$. A temperature coefficient $\mathrm{Q}_{10}$ was applied to the $\mathrm{O}_{2}$ fluxes. The $\mathrm{Q}_{10}$ represents the factor by which the bacterial activity increases for a rise of $10^{\circ} \mathrm{C}$ by the temperature (Thamdrup et al. 1998). This rate corresponds to the diffusive demand of oxygen related to 
the bacterial mineralization activity and a value of $\mathrm{Q}_{10}$ of 2.5 was assumed. The diffusive demand of oxygen at a given temperature $\mathrm{T}\left(\mathrm{DOU}_{\mathrm{T}}\right)$ was obtained using:

DOU $_{\mathrm{T}}=\frac{\mathrm{DOU}}{\mathrm{Ti}}$ 2.5 eq.1

Where $\mathrm{Q}_{10}=2.5$, $\mathrm{DOU}_{\mathrm{Ti}}$ is the diffusive demand of oxygen at initial temperature $\mathrm{Ti}$, $\mathrm{Ti}$ the initial temperature and $\mathrm{T}$ the final temperature.

\subsection{Statistical analyses}

Non-parametric Mann Whitney tests were used to compare oxygen penetration depths (OPD) and fluxes at different stations in each estuary and the potential seasonal differences of OPD and fluxes for a given station. We used the non-parametric Kruskal Wallis test to check the differences between stations in each estuary or between seasons for a given station. The Mann Whitney test was used to define which station (or season) was different from the other. For all tests, statistical differences were significant for $p<0.05$. The station E1 in February was not included in the statistics because only one profile was measured.

\section{Results}

\subsection{River parameters}

Wind speed amplitude, frequency, precipitations and river discharges were higher during winter and fall than in spring and summer (Raimonet 2011). For each estuary and at each season, sampling was undertaken at three different stations along the salinity gradient. Environmental parameters for each station and season are given in Table 1 and are described below. The high winter Elorn and Aulne river discharges increased up to 30 and $130 \mathrm{~m}^{3} \mathrm{~s}^{-1}$, respectively, at the beginning of sampling in February, and decreased by a factor $>2$ at the end of the sampling period. The Aulne River discharge was higher than the Elorn River discharge by a factor of $\sim 3$ during winter but similar or occasionally lower during summer.

In each estuary, the inner station was generally characterized by freshwater (salinity=0; Table 1) and brackish waters in October. The mid station was located in the mixing zone between fresh riverine water and salt water with a salinity ranging from 13-17 in February to 30 in October. The outer station was located near the mouth of each estuary and presented an average salinity higher than 20 and 30 in the Elorn and Aulne estuaries, respectively. The salinity at the outer station was always higher in the Elorn than the Aulne Estuary. As these 
estuaries are shallow, samplings in subtidal shores were carried out between 1 and $8 \mathrm{~m}$ depth. The bottom water temperatures followed a seasonal pattern and varied between a minimum of $7.4^{\circ} \mathrm{C}$ in February and a maximum of $19.7^{\circ} \mathrm{C}$ in July. The water temperatures were similar in the Elorn and Aulne estuaries during the different seasons. We observed a decrease in bottom water $\mathrm{O}_{2}$ concentrations from February to October for both estuaries. The water $\mathrm{O}_{2}$ concentrations were higher in the Aulne than Elorn Estuary, except in May.

\subsection{Variability at small spatial scales}

Spatial variations were studied at various small scales in May 2009 in the mid Elorn Estuary (station E2), at the centimeter scale (intra-core $\mathrm{O}_{2}$ profiles and fluxes), at the meter scale (triplicate cores \#1, \#2 and \#3) and along the cross-river section (stations E2, b, c, d and e). Fig.2 shows vertical profiles of $\mathrm{O}_{2}, \mathrm{NO}_{\mathrm{x}}{ }^{-}, \mathrm{NH}_{4}^{+}, \mathrm{Fe}^{2+}$ and $\mathrm{Mn}^{2+}$ concentrations and diffusive $\mathrm{O}_{2}$ uptakes (DOU) calculated at the centimeter and meter scales (left panels) and along the cross-section (right panels). Similar variability of $\mathrm{O}_{2}$, nutrient and metal profiles were observed at the centimeter and meter scales and along the cross-section. Oxygen penetration depth (OPD) and DOU observed in a core sampled at station E2 (OPD: 1.7-2.5 mm; DOU: $23 \pm 1 \mathrm{mmol} \mathrm{m}^{-2}$ day $^{-1}$; Fig.2a) were similar to the values measured along the transversal estuarine section (OPD: 1.7-2.1 mm; DOU: 20-22 mmol m² day ${ }^{-1}$ ). The penetration depth of $\mathrm{NO}_{\mathrm{x}}^{-}$was always 1.5-2.5 cm depth (Fig.2c). The same trends were observed for the vertical profiles of $\mathrm{NH}_{4}{ }^{+}, \mathrm{PO}_{4}{ }^{3-}$ and $\mathrm{Si}(\mathrm{OH})_{4}$ concentrations (the two latter are not shown; see Raimonet et al. in review) regardless of the small spatial scale. Pore water $\mathrm{NH}_{4}{ }^{+}$concentrations increased with depth with a lower concentration gradient generally observed between 6 and $12 \mathrm{~cm}$ depth. Pore water $\mathrm{NH}_{4}^{+}$concentrations were in the range of 20-250 $\mu \mathrm{M}$ except at deeper depth where concentrations reached up to $1000 \mu \mathrm{M}$ at $18 \mathrm{~cm}$ at station E2. The lowest $\mathrm{NH}_{4}^{+}$concentrations were measured in and around the channel (at stations b, c, d), whereas the highest concentrations were measured in subtidal shores (at 0-8 $\mathrm{cm}$ depth at station e, and below 8 $\mathrm{cm}$ at station E2). Maximal $\mathrm{Mn}^{2+}$ concentrations were always observed between 0 and $2 \mathrm{~cm}$ depth. Low variations in the vertical $\mathrm{Mn}^{2+}$ profiles were observed at all stations, except higher $\mathrm{Mn}^{2+}$ concentrations in the first $1.5 \mathrm{~cm}$ depth in the channel (note that there is no data between 1.5 and $6 \mathrm{~cm}$ ). The vertical $\mathrm{Fe}^{2+}$ concentration $^{2+}$ profiles were more variable than other elements at the centimeter and meter scale and along the transversal section. The shape of the vertical $\mathrm{Fe}^{2+}$ concentration profiles was however similar with concentration peaks observed down to the maximal $\mathrm{Mn}^{2+}$ concentrations. As for $\mathrm{NH}_{4}{ }^{+}$concentrations, the lowest $\mathrm{Mn}^{2+}$ concentrations were observed close to the channel. 


\subsection{Intra- and inter-estuary spatial variability}

\subsubsection{Porosity and salinity}

Porosity generally decreased with depth at all stations in February and May, ranging between 0.67-0.95 regardless of stations and seasons (Fig.3). Several vertical discontinuities were observed however in the inner and mid Elorn Estuary in February and in the mid and outer Aulne Estuary in May. Salinity slightly increased with depth at all stations in February and in the inner Elorn Estuary (E1) in May. Except for station E1, salinity was constant over depth at all stations in May (Fig.4). In both estuaries, salinity increased from the inner to the outer estuaries.

\subsubsection{Organic carbon and isotopic composition in surface sediments}

Both estuaries had similar organic carbon contents in February and showed large variations along the salinity gradient during the other seasons (Fig.5a and b). Low organic carbon contents were observed in outer estuaries (stations E3 and A3). Most organic carbon contents ranged between 1.5 and 6.0\% d.w. in both estuaries, with higher values ( 7.0\% d.w.) at E1 in July and at A2 in October. Organic carbon contents generally decreased downstream, except in October in both estuaries and in July in the Elorn Estuary where the mid brackish station showed a larger organic carbon content than the upper freshwater station. Organic carbon contents were always lower at the outer than upper stations.

The Fig.5c and d show the carbon to nitrogen molar ratios $(\mathrm{C} / \mathrm{N})$ in surficial sediments for the different seasons. Inner and mid estuaries (stations 1 and 2) displayed similar $\mathrm{C} / \mathrm{N}$ ratios $\geq 10$, except in the Elorn Estuary in October. Outer estuaries (station 3) always showed values $\leq 9$ in the Elorn Estuary and between 9 and 11 in the Aulne Estuary.

$\delta^{13} \mathrm{C}$ values were generally higher in the Elorn than the Aulne Estuary (Fig.5e and f). $\delta^{13} \mathrm{C}$ values were similar in all seasons in the inner and mid Elorn and Aulne estuaries, except in October in the Aulne Estuary. The outer estuary (station 3) showed higher values than inner and mid stations for both estuaries, this difference being larger in the Elorn than the Aulne Estuary. $\delta^{13} C$ values were seasonally stable in the Elorn Estuary, whereas they showed a 0.6-0.7\%o decrease from February to October in the Aulne Estuary.

\subsubsection{Oxygen profiles}

The $\mathrm{O}_{2}$ bottom water concentrations $\left(\mathrm{O}_{2 \mathrm{bw}}\right)$ decreased by about $20 \%$ along the salinity gradient in each estuary in February (Fig.6a and b). At other seasons, except in July in the Aulne Estuary, there was a decrease 
from inner to mid estuaries but low variations in the outer estuaries (Fig.6c and h). The decrease in $\mathrm{O}_{2 b w}$ concentrations slightly coincided with a decrease in the thickness of the oxic zone.

The $\mathrm{O}_{2}$ penetration depth was low and varied from $1.15 \pm 0.10 \mathrm{~mm}$ at E2 in February to $5.10 \pm 0.42 \mathrm{~mm}$ at A3 in February. Overall, the $\mathrm{O}_{2}$ penetration depths were larger in the Aulne than the Elorn Estuary (Fig.6i and j). Penetration depths of $\mathrm{O}_{2}$ were generally lower at mid stations (A2 and E2) than outer stations (A3 and E3). There was a difference between the inner estuary stations of the Aulne and Elorn estuaries. In the inner estuaries, the penetration depth of $\mathrm{O}_{2}$ was larger in the Aulne (A1) than Elorn sediments (E1). Penetration depths of $\mathrm{O}_{2}$ were only slightly higher at the inner station E1 than at the mid station E2. There was no seasonal trend for $\mathrm{O}_{2}$ penetration depth in sediments of these two estuaries.

\subsubsection{Nutrient and metal profiles}

Inorganic oxidized nitrogen $\left(\mathrm{NO}_{\mathrm{x}}{ }^{-}\right)$concentrations in the overlying water (Fig.7a and b, 8a and b) were the highest in the inner and mid Elorn stations, varying between 500-520 $\mu \mathrm{M}$ (E1) and 150-498 $\mu \mathrm{M}$ (E2). Lower concentrations, between 7 and $63 \mu \mathrm{M}$, were measured in the outer estuary (E3). In addition to this difference along the estuary, $\mathrm{NO}_{\mathrm{x}}^{-}$concentrations decreased between February and May for the inner and intermediate stations E2 and E3. In the Aulne Estuary, pore water $\mathrm{NO}_{\mathrm{x}}{ }^{-}$concentrations decreased from inner estuary (A1: 145$250 \mu \mathrm{M}$ ) to outer or mid estuary (around 30-100 $\mu \mathrm{M}$ ) and from February to May at A1 and A3. An increase from February to May was observed at A2 (from 13 to $65 \mu \mathrm{M}$ ).

Pore water $\mathrm{NO}_{\mathrm{x}}{ }^{-}$profiles exhibited similar patterns in the Elorn and Aulne estuaries (Figs.7c and d, 8c and d). All pore water $\mathrm{NO}_{\mathrm{x}}^{-}$profiles showed a strong decrease in concentrations with depth. At all stations, $\mathrm{NO}_{\mathrm{x}}^{-}$ concentrations were below the detection limit at a depth of 1-4 cm in February and below 1-2 cm depth in May. The lowest $\mathrm{NO}_{\mathrm{x}}^{-}$penetration depths occurred in the mid and outer Elorn Estuary (E2 and E3). Little seasonal variation regarding the $\mathrm{NO}_{\mathrm{x}}^{-}$pore water profiles was observed at stations E2 and E3. In the Aulne Estuary, elevated $\mathrm{NO}_{\mathrm{x}}^{-}$concentrations were determined in the bottom water and top $1 \mathrm{~cm}$ of sediment, whereas below the detection limit at depth (below 2-4 cm). The lowest penetration depths of $\mathrm{NO}_{\mathrm{x}}{ }^{-}$were observed in May.

For all sites in the Elorn and Aulne estuaries, the concentration of $\mathrm{Fe}^{2+}$ in the overlying water was lower than 3 $\mu \mathrm{M}$ (Figs.7e and $\mathrm{f}, 8 \mathrm{e}$ and $\mathrm{f}$ ). The pore water profiles of $\mathrm{Fe}^{2+}$ were characterized by an increase at depth coinciding with the depth at which $\mathrm{NO}_{\mathrm{x}}{ }^{-}$disappeared. Below this depth, in the Elorn Estuary, $\mathrm{Fe}^{2+}$ concentrations up to $200 \mu \mathrm{M}$ (E2, E3) and $50 \mu \mathrm{M}$ (E1) were detected. At deeper depth, $\mathrm{Fe}^{2+}$ concentrations decreased and were absent below $5 \mathrm{~cm}$ depth. Furthermore, little seasonal variation was observed regarding the pore water $\mathrm{Fe}^{2+}$ 
profiles. Pore water $\mathrm{Mn}^{2+}$ were very similar to the $\mathrm{Fe}^{2+}$ depth profiles, with 20 fold lower concentrations. The $\mathrm{Fe}^{2+}$ pore water profiles showed a larger variability in the Aulne compared to the Elorn Estuary. A typical subsurface peak, as in the Elorn Estuary, was observed in the outer station (A3, $200 \mu \mathrm{M})$. A similar depth profile was also present at the intermediate station (A2), however the $\mathrm{Fe}^{2+}$ concentrations reached values up to $1500 \mu \mathrm{M}$ (February) and $2000 \mu \mathrm{M}$ (May). No typical subsurface peak in $\mathrm{Fe}^{2+}$ was observed in the inner estuary (A1); pore water $\mathrm{Fe}^{2+}$ concentrations gradually increased up to $14 \mathrm{~cm}$ depth at $\mathrm{A} 1(700 \mu \mathrm{M})$. Profiles of pore water $\mathrm{Mn}^{2+}$ concentrations displayed similar patterns, with a subsurface peak, as $\mathrm{Fe}^{2+}$, at 50 fold lower concentrations. In contrast to the $\mathrm{Fe}^{2+}$ concentrations, $\mathrm{Mn}^{2+}$ was still present at deeper depth.

Overall $\mathrm{NH}_{4}{ }^{+}$concentrations were low in the overlying water at the different locations in the Elorn Estuary as well as throughout the different seasons $\left(<10 \mu \mathrm{M}\right.$; Figs.7g and h, $8 \mathrm{~g}$ and h). The pore water profiles of $\mathrm{NH}_{4}{ }^{+}$ concentrations gradually increased from 10-20 $\mu \mathrm{M}$ in the surficial sediment up to $1200 \mu \mathrm{M}$ in the deeper layers. In February, $\mathrm{NH}_{4}{ }^{+}$profiles displayed a greater spatial variability; the mid station (E2) showed a particular pattern with concentrations about 2 to 6 times higher than at E1 and E3 and about 2 times higher in February than in May (up to $2400 \mu \mathrm{M}$ ). In the inner estuary (E1), $\mathrm{NH}_{4}{ }^{+}$concentrations, at deeper depth, increased from $400 \mu \mathrm{M}$ in February to $900 \mu \mathrm{M}$ in May. In the outer estuary (E3), concentrations were similar in February and May. Similar to the Elorn Estuary, $\mathrm{NH}_{4}^{+}$profiles (February) showed concentrations in the inner estuary (A1) up to 2.5 times higher than in the mid and outer estuary (A2 and A3) and higher than in May. In May, $\mathrm{NH}_{4}^{+}$profiles showed similar patterns than in the Elorn Estuary, with little spatial variability and concentrations increasing with depth up to $1200 \mu \mathrm{M}$ in the outer estuary (A3).

$\mathrm{SO}_{4}{ }^{2-}$ concentrations in the overlying water were low in the inner Elorn and Aulne estuaries ( $\sim 5 \mathrm{mM}$; Fig.7i and j) and high in the mid (10-18 mM) and outer estuary (18-31 mM). Similar trends were observed in May (Fig.8i and j). Little variation in these concentrations was observed with depth in the inner and mid Elorn Estuary, whereas a decrease at deeper depth was observed at the outer station (E3). High and comparable $\mathrm{SO}_{4}{ }^{2-}$ concentration profiles were measured at the mid and outer Aulne estuary, decreasing from $20 \mathrm{mM}$ at the sediment-water interface to $14 \mathrm{mM}$ at $12 \mathrm{~cm}$ depth (Figs.7j and 8j).

No $\mathrm{H}_{2} \mathrm{~S}$ was detectable in the Elorn and Aulne sediments in February (Fig.7k and l). In May, $\mathrm{H}_{2} \mathrm{~S}$ concentrations were below the detection limit in the top layers of the sediment and at the intermediate station (E2; Fig.8k). Concentrations of $\mathrm{H}_{2} \mathrm{~S}$ up to $40 \mu \mathrm{M}$ were detected at a depth below $5 \mathrm{~cm}$ at the inner station (E1). At the outer station (E3), concentrations increased with depth below $16 \mathrm{~cm}$ and reached up to $100 \mu \mathrm{M}$ at $20 \mathrm{~cm} . \mathrm{H}_{2} \mathrm{~S}$ concentrations in the Aulne estuary were low in May, with only traces measured at the mid station (A2; Fig.81). 


\subsection{Seasonal variability of diffusive $\mathrm{O}_{2}$ fluxes}

The mean diffusive $\mathrm{O}_{2}$ fluxes calculated at the three stations in the Elorn and Aulne estuaries and at each season are shown in Fig.9a and b. In both estuaries except mid stations, diffusive $\mathrm{O}_{2}$ fluxes were higher in May and July than in February and, in a smaller extent, in October. At mid stations (E2 and A2), diffusive $\mathrm{O}_{2}$ fluxes were similar over the year, with a small drop in October.

The diffusive $\mathrm{O}_{2}$ fluxes recalculated for a temperature of $10^{\circ} \mathrm{C}$ using the temperature $\mathrm{Q}_{10}$ relationship (Thamdrup et al. 1998) for each station and season are presented in Fig.9c and d. In the Elorn and Aulne estuaries, we observed higher T-corrected (Fig.9c and d) than not corrected (Fig.9a and b) diffusive $\mathrm{O}_{2}$ fluxes in February but lower T-corrected diffusive $\mathrm{O}_{2}$ fluxes in May, July and October. Once normalized to a fixed temperature, the seasonal variation with larger values in spring and summer was smoothed out at station E1, E3 and A3. Some inverse decreasing trend from February-May to July-October appeared at stations E2, A1, A2.

\section{Discussion}

\subsection{Benthic heterogeneity at station and cross-estuary scales}

The similarity of the vertical profiles of $\mathrm{O}_{2}$, nutrient and metal concentrations at the station scale (within meters of the exact location) and cross-section scale highlights the relative homogeneity of benthic properties in the mid estuary. This low heterogeneity at the station scale allows temporal variability to be studied. The variability of pore water profiles of $\mathrm{NH}_{4}{ }^{+}, \mathrm{Fe}^{2+}$ and $\mathrm{Mn}^{2+}$ at the cross-section and station scales is much lower than the variability observed between estuaries and along salinity gradients. The low cross-section variability observed in this study suggests thus that biogeochemical heterogeneity might be low in estuaries characterized by a small channel width, contrary to higher variations observed in larger systems (e.g. Hammond et al. 1985; Grenz et al. 2000), or by measurements of net benthic fluxes that integrate all benthic processes (Hammond et al. 1985; Thouzeau et al. 2007).

Although $\mathrm{O}_{2}$ variability is low in the whole cross-section, nutrient and metal concentrations are slightly lower in the channel compared the subtidal shores, suggesting slight differences in benthic biogeochemical processes. Channel sediments might have been characterized by lower organic matter inputs and benthic macrofauna activity (as already suggested by benthic fluxes measurements in San Francisco Bay; Hammond et al. 1985), which could have led to slower diagenetic processes in the channel. It is worth noting that opposite trends can be observed in larger and more productive areas where benthic remineralization is higher in the channel compared to the shoal (Grenz et al. 2000). 
The relatively low variability of benthic pore water properties is however in contrast with general high benthic heterogeneity due to processes that occur in surficial sediments in coastal ecosystems, e.g., heterogeneous distribution of benthic macrofauna and/or primary producers, sediment porosity variability, microtopography, local deposition of labile organic matter, micro-scale turbulence, and resuspension-deposition events (Huettel et al. 2003; Rabouille et al. 2003, Glud 2008; Mügler et al. 2012). The heterogeneity is sometimes high enough to prevent the study of seasonal variations (Bay of Biscay; Mouret et al. 2009). The results of our study show that benthic heterogeneity in inner estuarine sections characterized by a small channel area is low. The low variability of triplicate profiles and fluxes of $\mathrm{O}_{2}$ and the sampling at the same station on the left subtidal shore allows studying seasonal variations of diffusive $\mathrm{O}_{2}$ fluxes in the two estuaries.

\subsection{Seasonal variations at the estuary scale}

Increases in salinity from winter to spring have to be considered with respect to hydrologic records. For instance, the average daily discharge in the Aulne River ranged between 100 and $200 \mathrm{~m}^{3} \mathrm{~s}^{-1}$ in January-February 2009 but only $20 \mathrm{~m}^{3} \mathrm{~s}^{-1}$ in April-May. In the Elorn River, average daily discharge dropped from $12-30 \mathrm{~m}^{3} \mathrm{~s}^{-1}$ to 5 $\mathrm{m}^{3} \mathrm{~s}^{-1}$.

If pore water salinity is a good tracer of overlying water salinity and thus of seasonal hydrological conditions, pore water chemical composition would respond at least partially to seasonal changes. Especially, the rate of sulfate reduction most likely increases in May, not only due to temperature changes, but also due to higher sulfate resupply still observable in the mid Elorn Estuary in May. Higher sulfate reduction rates in sediment or lower sulfide control by FeS precipitation lead to higher $\mathrm{H}_{2} \mathrm{~S}$ concentration in pore waters in May, especially in the Elorn Estuary. However, for electron acceptors ubiquitously present in fresh or marine waters $\left(\mathrm{O}_{2}, \mathrm{NO}_{3}{ }^{-}\right.$, $\mathrm{MnO}_{2}, \mathrm{FeOOH}$ ), diffusive and advective supplies (in zones of coarser sediments) related to salinity changes will have little effect on early diagenetic processes related to those chemical species. This statement may provide an explanation for the lack of significant seasonal variation regarding ammonium profiles. Consequently, variability of early diagenesis processes in and between those two estuaries is expected to be controlled by organic matter deposition and seasonal changes in temperature rather than salinity changes.

The role of the benthic fauna on oxygen profiles and diffusive fluxes might have been limited in this study, even if benthic fauna was present in these estuaries (except at stations A1 and A2; Michaud pers. comm.; Raimonet 2011). The presence of benthic fauna has already been shown to increase total benthic oxygen fluxes depending on the bioturbation strategy and feeding activity which vary among species (Michaud et al. 2005). Here, we 
report diffusive oxygen uptake, i.e. when measurements of oxygen profiles were performed in sediments out of animal burrows in order to avoid the interference with benthic fauna. The similarity between replicate oxygen profiles and the absence of vertical discontinuities in oxygen profiles confirms the homogeneity of the sediments with regards to the diffusive uptake of oxygen.

Overall, sediment oxygen demands are larger in the Elorn compared to the Aulne estuarine sediments. The seasonal trend is well marked with an increase during spring and summer (May and July) for all stations, except in the mid Elorn Estuary. Sediment oxygen demand is lower during winter and fall (February and October). This seasonal variation gives rise to a bell-curve pattern for the temporal evolution at each station (Fig.9). This pattern is largely related to the seasonal evolution of temperature typically observed in mid-latitude regions (Dedieu et al. 2007). In this temperate and oceanic system, temperature in the bottom estuarine water increases by $10^{\circ} \mathrm{C}$ between $<8^{\circ} \mathrm{C}$ in winter and $18^{\circ} \mathrm{C}$ in summer (Table 1). Temperature increases diffusion coefficients as well as aerobic microbial activity resulting in higher oxygen fluxes.

The lower seasonal variations of oxygen fluxes at intermediate salinities (E2 or A2) suggest that other factors, such as organic carbon loading and dissolved oxygen concentrations, might vary at the seasonal scale and decrease the range of seasonal variations in the benthic oxygen demand. Oxygen fluxes were thus normalized to a common temperature of $10^{\circ} \mathrm{C}$ in order to limit the temperature effect and estimate the influence of other parameters. T-corrected diffusive oxygen fluxes show a different seasonal variation than diffusive oxygen fluxes calculated at in situ temperature (Fig.9c and d). They indicate a relatively stable trend for stations E1, E3 or A3, whereas a clear and progressive seasonal decrease from February to October is observed for mid stations E2 and A2 and, to a lesser extent, at the upper station A1. The change in oxygen concentration in the bottom water, largely due to seasonal changes in temperature and salinity, partly explains this decrease with time. It is known that oxygen concentration in bottom waters influences oxygen fluxes as they mechanically decrease the gradient for a given microbial consumption in the sediment (Hall et al. 1989; Rabouille and Gaillard 1994; Cai et al. 1995). Yet, this dependence is small if the oxygen concentration in the bottom water remains above $75 \mu \mathrm{M}$ (Cai et al. 1995). In the two mid estuaries where the decrease in oxygen flux is the most pronounced, oxygen concentrations and diffusive T-corrected oxygen fluxes are closely linked $\left(r^{2}=0.95\right)$. However, the observed sensitivity of the T-corrected diffusive oxygen flux to the oxygen concentration change during the year is very high as T-corrected diffusive oxygen fluxes are divided by 3 or more for a reduction of oxygen by only 100-150 $\mu \mathrm{M}$ (30-40\% of the initial value). This large decrease of $\mathrm{O}_{2}$ fluxes points towards other processes correlated to the seasonal decrease in oxygen concentration, such as changes in organic matter input or its reactivity. 
Contrasted temporal variations of T-corrected diffusive oxygen fluxes in the Elorn and Aulne estuaries suggest differences in the factors controlling the seasonal variations of benthic diffusive oxygen flux. In the Elorn Estuary, T-corrected diffusive oxygen fluxes decrease from upstream to downstream at most seasons except in February where a peak at intermediate salinity (E2) occur. At station E2, a large temporal variability of Tcorrected fluxes along the year is observed as fluxes vary from 10 to $25 \mathrm{mmol} \mathrm{m}^{-2}$ day $^{-1}$. The situation is different in the Aulne Estuary where T-corrected sediment oxygen fluxes are rather constant from the inner to outer estuary with lower seasonal variability at each station. Both the large seasonal variations of benthic diffusive oxygen flux and its spatial pattern along the estuaries suggest that a large input of labile organic matter occurring during the winter might be slowly mineralized during the year at the mid estuary as it has already been shown in different estuarine, coastal and marine environments (Gehlen et al. 1997; Cathalot et al. 2010, Cathalot et al. 2012). This phenomenon more pronounced in Elorn that in Aulne Estuary, might be correlated with the oxygen reduction in bottom water, and would provide the spatial pattern observed in Fig.10. In addition, if this effect is lower in the Aulne Estuary, then lower oxygen fluxes are expected as currently observed. Clearly, a modelling approach is needed to disentangle the various forcing on organic matter mineralization which is the driving force of oxygen fluxes in these sediments.

\subsection{Organic matter flux and quality}

In temperate estuaries and deltas, the origin of organic matter and its potential reactivity is complex and is linked to different types of organic matter: terrestrial, riverine, marine and urban waste (Cifuentes et al. 1988; Barth et al. 1998; Hellings et al. 1999; Lansard et al. 2009; Xiao and Liu 2010; Pastor et al. 2011b). In estuarine environments, the composition of organic matter in the upper sediment layer that is mineralized responds seasonally to the changes in the composition of suspended particles.

In the Aulne and Elorn estuaries, a seasonally reproducible pattern of organic carbon content, $\mathrm{C} / \mathrm{N}$ ratio and $\delta^{13} \mathrm{C}$ is found along the estuary (Fig.5). Organic carbon content and C/N ratio are high in upper sediments (4-6\% d.w. and 11-15, respectively) and decrease downstream to values around $2 \%$ d.w. and $\mathrm{C} / \mathrm{N} \leq 10$. The amplitude of this seaward decrease varies with the season. It is less pronounced in winter and increases in spring, summer and fall. The decrease of organic carbon content and $\mathrm{C} / \mathrm{N}$ ratio suggests that the carbon transported by the rivers into the estuaries is diluted, mineralized and mixed with marine organic carbon characterized by lower $\mathrm{C} / \mathrm{N}$, typically around 7-8 for fresh phytoplankton (Tesi et al. 2007; Lansard et al. 2009). The carbon isotopic composition also shows a stable pattern throughout the seasons and in the two estuaries. The $\delta^{13} \mathrm{C}$ of organic carbon increases 
seaward from similar values in the inner parts of the two estuaries to significantly higher $\delta^{13} \mathrm{C}$ in outer estuaries. The simultaneous increase of $\delta^{13} \mathrm{C}$ and decrease of $\mathrm{C} / \mathrm{N}$ confirm the seaward increase in marine organic material. A plot of N/C against $\delta^{13} \mathrm{C}$ shows a clear mixing trend between two end-members: (1) plant debris and soil organic matter with lower $\mathrm{N} / \mathrm{C}$ and $\delta^{13} \mathrm{C}$, and (2) marine phytoplankton with larger N/C and $\delta^{13} \mathrm{C}$ (Fig.11). A difference in the absolute values of $\delta^{13} \mathrm{C}$ and N/C however appears between the two estuaries, the organic matter showing always lower $\delta^{13} \mathrm{C}$ and N/C values in the Aulne than the Elorn Estuary. This could be biased by the fact that the outer Elorn station (E3) showed consistently larger salinities than the outer Aulne station (A3), indicating a higher contribution of marine organic matter. However, the addition of a station further downstream of the Aulne Estuary (A4, Fig.11) at salinity similar to the outer Elorn station, still showed lower values than the outer Elorn station ( $\mathrm{N} / \mathrm{C} \approx 0.12$ and $\delta^{13} \mathrm{C} \approx-24.5 \%$ ). The difference in the organic carbon signature in surface sediments between the two estuaries points thus rather towards a different origin of organic matter. Plants and soils are very similar in the two drainage basins that are geographically, climatically and geologically close. A difference between both drainage basins exists however in the human activities and the river morphology and hydrology (Fraisse et al., submitted). The Elorn River drains a mixed countryside and small cities watershed (220 inhabitants $\mathrm{km}^{-2}$ ) with intensive pig and caw farming and important river channelling. The Aulne watershed is characterized by agricultural activities and numerous dams and river locks. Therefore, the Elorn River has little production of riverine plankton because of the short residence time of the water although nutrient concentrations are high and receives sewage/farm organic matter inputs. The Aulne Estuary shows larger values of chlorophyll $a$ in its upper reaches and in the estuary itself (Fraisse et al., submitted), and may carry a larger proportion of river phytoplankton into the estuary.

The isotopic and elemental signature of sewage organic matter are close to the mix of terrestrial plants and soils (Ruiz-Fernández et al. 2002; Xiao and Liu 2010), as sewage inputs show $\delta{ }^{13} \mathrm{C}$ of -25\%o and C/N of 12 (N/C = 0.08). These values are typically observed in the Elorn Estuary (Fig.5), which highlight the possible load of sewage and the similar contents of terrestrial and marine matter. In order to explain lower $\delta{ }^{13} \mathrm{C}$ in the Aulne Estuary, it is noteworthy that phytoplankton is dependent on the $\delta{ }^{13} \mathrm{C}$ of dissolved inorganic carbon (DIC) in the river in which they grow. As Brittany rivers contain low DIC due to the granitic nature of watershed, $\delta{ }^{13} \mathrm{C}$ of DIC may be largely influenced by remineralization in the river and may produce negative values, thus lowering the $\delta{ }^{13} \mathrm{C}$ of riverine phytoplankton as shown in the Delaware estuary (Cifuentes et al. 1988). The differential input of sewage (-25\%) in the Elorn estuary and phytoplankton (maybe as low as -28\%o) in the Aulne estuary may explain the lower $\delta{ }^{13} \mathrm{C}$ values in the organic carbon of the Aulne Estuary versus the Elorn Estuary. 


\subsection{Organic matter mineralization in estuaries}

Overall, the release of $\mathrm{NH}_{4}^{+}$during the organic matter degradation is reflected by an increase in concentration with depth (e.g Berg et al. 2003; Canavan et al. 2006). Comparable $\mathrm{NH}_{4}{ }^{+}$pore water profiles, with a few exceptions, regardless stations and seasons suggest similar organic matter mineralization rates per station during the different seasons for both estuaries. Higher $\mathrm{NH}_{4}{ }^{+}$concentrations observed in February at stations E2 and A1 indicate higher anaerobic mineralisation rates at these two stations, which is also highlighted by the formation of authigenic phosphorus in the upper Aulne Estuary (Raimonet et al. in review).

The pore water profiles and associated diffusive fluxes of $\mathrm{O}_{2}$ indicate slightly higher aerobic organic matter degradation in the Elorn compared to the Aulne Estuary, which highlight more reactive organic matter in the top layers in the Elorn Estuary. The high $\mathrm{NO}_{3}{ }^{-}$concentrations in the overlying water, larger than oxygen concentration in these $\mathrm{NO}_{3}^{-}$-rich estuarine waters, especially in the inner estuaries, most likely contribute largely to organic matter degradation in the oxic to suboxic top layer (e.g. Berg et al. 1998). The contribution of $\mathrm{NO}_{3}{ }^{-}$ reduction to organic matter mineralisation is less important in the outer estuary, due to lower concentrations in the overlying water.

In the deeper anoxic layers, below the oxygen and nitrate penetration depths, iron and manganese oxides and sulphate play a role in the further degradation of the organic matter. The low concentrations of reduced $\mathrm{Fe}^{2+}$ and $\mathrm{Mn}^{2+}$ at depth in the Elorn Estuary compared to the Aulne Estuary indicate a limited contribution of metal oxides in the organic matter mineralisation. Higher pore water concentration of iron and manganese are observed in the Aulne Estuary (especially at the intermediate station), resulting in a higher contribution of Fe and Mn oxides to anoxic mineralisation of organic matter. High $\mathrm{SO}_{4}{ }^{2-}$ concentrations in the overlying water and a decrease in the pore waters in the mid and outer sediments of the Aulne Estuary for example suggest a role of $\mathrm{SO}_{4}{ }^{2-}$ reduction in the mineralisation of the organic matter. This is confirmed by the slight decrease in $\mathrm{SO}_{4}{ }^{2-}$ concentrations (with a few exceptions) and the production of $\mathrm{H}_{2} \mathrm{~S}$ (E1, E3 May) at deeper depth. The production of $\mathrm{H}_{2} \mathrm{~S}$ during $\mathrm{SO}_{4}{ }^{2-}$ reduction and the absence of this compound at deeper depths can be explained by the precipitation of $\mathrm{HS}^{-}$with $\mathrm{Fe}^{2+}$.

In order to establish quantitative estimations of the different processes contributing to the degradation of organic matter a modelling approach is needed. 


\section{Conclusion}

In this paper, we determined the spatio-temporal distribution of benthic oxygen, pore water nutrients and metals along the salinity gradients during four seasons. The variability of pore water profiles of $\mathrm{NH}_{4}^{+}, \mathrm{Fe}^{2+}$ and $\mathrm{Mn}^{2+}$ at the cross-section and station scales is much lower than the variability observed between estuaries and along salinity gradients. The low cross-section variability observed in this study suggests thus that biogeochemical heterogeneity might be low in estuaries characterized by a small channel width. Overall, sediment oxygen demands are larger in the Elorn compared to the Aulne estuarine sediments. Suboxic and anoxic organic matter mineralization is variable over the seasons and indicates large nitrate consumption, large anoxic mineralization as exemplified by pore water $\mathrm{NH}_{4}^{+}$gradients in both estuaries and sulphate reduction in the Elorn Estuary. The role of metal oxides in early diagenesis seems to be limited but interactions with other compounds such as sulphide may limit their concentration. Organic carbon and nitrogen analyses indicate that the origin of carbon is different in the two watersheds with lighter $\delta^{13} \mathrm{C}$ of carbon in the Elorn watershed linked to urban sewage or farm inputs. The lability of these inputs could lead to larger mineralization in upstream stations of this estuary compared to the Aulne Estuary. A modelling approach is needed to quantify the relative strength of the different early mineralization pathways and understand the forcing on organic matter mineralization in these contrasted estuaries.

\section{Acknowledgments}

This work was financed by EC2CO Moitem-Estuaires. The authors thank the crew of N/O Côtes de la Manche, Bruno Bombled, Manon Le Goff, Xavier Philippon, Agnès Youenou, Roger Kérouel Julien Queré, Erwan Amice and Robert Marc for their technical support.

\section{References}

Aminot A, Kerouel R, Coverly SC (2009) Nutrients in seawater using segmented flow analysis, CRC Press, Boca Raton, pp 143-178

Andrieux-Loyer F, Philippon X, Bally G, K’erouel R, Youenou A, Le Grand J (2008) Phosphorus dynamics and bioavailability in sediments of the Penz'e Estuary (NW France): in relation to annual p-fluxes and occurrences of Alexandrium minutum. Biogeochemistry 88(3):213-231

Barth JAC,Veizer J, Mayer B (1998) Origin of particulate organic carbon in the upper St. Lawrence: isotopic constraints. Earth Planet Sci Let 162: 111-121

Berg P, Risgaard-Petersen N, Rysgaard S (1998) Interpretation of measured concentration profiles in sediment pore water. Limnol Oceanogr 43: 1500-1510 
Berg P, Rysgaard S, Thamdrup B (2003) Dynamic modeling of early diagenesis and nutrient cycling. A case study in an Arctic marine sediment. American Journal of Science 303: 905-955

Berner RA (1980) Early diagenesis: A Theoretical Approach. Princeton University Press, 241 pp

Bopp RF, Simpson HJ, Olsen CR, Trier RM, Kostyc N (1982) Chlorinated hydrocarbons and radionuclides chronologies in sediments of the Hudson river and estuary, New York. Environ. Sci. Technol. 16: 666-676

Broecker WS, PENG TH (1974) Gas exchange rates between air and sea. Lamont-Doherty Geological: 21-35

Burgin AJ, Hamilton SK (2007). Have we overemphasized the role of denitrification in aquatic ecosystems? A review of nitrate removal pathways. Front. Ecol. Environ. 5(2): 89-96

Cai WJ, Reimers CE (1995) Benthic oxygen flux, bottom water oxygen concentration and core top organic carbon content in the deep northeast Pacific ocean. Deep-Sea Res. 42: 1681-1699

Canavan RW, Slomp CP, Jourabchi P, Van Cappellen P, Laverman AM, Van den Berg GA (2006) Organic matter mineralization in sediment of a coastal freshwater lake and response to salinization. Geochimica Et Cosmochimica Acta 70: 2836-2855

Canfield DE, Jorgensen BB, Fossing H, Glud R, Gundersen J,Ramsing NB, Thamdrup B, Hansen JW, Nielsen LP, Hall POJ (1993) Pathways of organic carbon oxidation in three continental margin sediments. Marine Geology 113(1-2): 27-40

Cathalot C, Rabouille C, Pastor L, Deflandre B, Viollier E, Buscail R, Grémare A, Treignier C, Pruski A (2010) Temporal variability of carbonrecycling in coastalsedimentsinfluenced by rivers: assessing the impact of flood inputs in the Rhône River prodelta. Biogeosciences 7: 1187-1205

Cathalot C, Lansard B, Hall Per OJ, Tengberg A, Almroth-Rosell E, Apler A, Calder L, Bell E, Rabouille C (2012) Loch Impacted by Fish Farming: A Combination of In Situ Techniques. Aquat. Geochem. doi:10.1007/s10498-012-9181-4

Cifuentes LA, Sharp JH, Fogel ML (1988) Stable carbon and nitrogen isotope biogeochemistry in the Delaware estuary. Limnol. Oceanogr. 33: 1102-1115

Cloern JE (1996) Phytoplankton bloom dynamics in coastal ecosystems: A review with some general lessons from sustained investigation of San Francisco Bay, California, Rev. Geophys. 34: 127-168, doi:110.1029/1096RG00986 
Cloern JE, Jassby AD (2012) Drivers of change in estuarine-coastal ecosystems: Discoveries from four decades of study in San Francisco Bay. Rev. Geophys. 50, RG4001, doi:4010.1029/2012RG000397

Deflandre B., Mucci A, Gagné JP, Guignard C, Sundby B (2002) Early diagenetic processes in coastal marine sediments disturbed by a catastrophic sedimentation event. Geochim Cosmochim Acta 66 : 2547-2558

Del Amo Y (1996) Dynamique des structure des communautés phytoplanctoniques en écosystèmes côtiers perturbé ; cinétique del’incorporation du silicium par les diatomées. Thèse de Doctorat, Université de Bretagne Occidentale, Brest

Fraisse S., M. Bormans,Y. Lagadeuc (submitted) Phytoplankton community in rivers: a morphofunctional traits approach submitted Aquatic Ecology

Gauthier C, Hatté C (2007) Suitability and reliability of isotopic biogeochemistry studies in paleoclimatology: focus on protocols. In Geophysical Research Abstracts EGU 200702912

Gehlen M., Rabouille C, Guidi-Guilvard LD, Ezat U (1997) Drastic changes in deep-sea sediment porewater composition induced by episodic input of organic matter. Limnol Oceanogr 42: 980-986

Glud RN (2008) Oxygen dynamics of marine sediments. Marine Biology Research 4(4): 243-289

Grasshoff K, Ehrhardt M, Kremling K (1983) Methods of Seawater Analysis, second, revised and extended edition. Verlag Chemie, Weinheim, Germany, 420 pp

Grenz C, Cloern JE, Hager SW, Cole BE (2000) Dynamics of nutrient cycling and related benthic nutrient and oxygen fluxes during a spring phytoplankton bloom in South San Francisco Bay (USA). Marine Ecology Progress Series 197: 67-80

Hall. PDJ, Anderson. LG, Rutger van der, Loeff. MM, Snudby B, Vesterlund. SFG (1989) Oxygen uptake kinetics in the benthic boundary layer. Limnol. Oceanogr. 34: 734-746

Hammond DE, Fuller C, Harmon D, Hartman B, Korosec M, Miller LG, Rea R, Warren S, Berelson W, Hager SW (1985) Benthic fluxes in San Francisco Bay. Hydrobiologia 129(1): 69-90

Hellings L,Dehairs F, Tackx M, Keppens E, Baeyens W (1999) Origin and fate of organic carbon in the freshwater part of the Scheldt Estuary as traced by the stable carbon isotope composition. Biogeochemistry 47: 167-186

Huettel M, Røy H, Precht E, Ehrenhauss S (2003) Hydrodynamical impact on biogeochemical processes in aquatic sediments. Hydrobiologia 494: 231-236 
640 Lansard B, Rabouille C, Denis L, Grenz C (2009) Benthic remineralization at the land-ocean interface: A case

641 study of the Rhone River (NW Mediterranean Sea). Estuarine, Coastal and Shelf Science 81(4): 544-554

642

643

644

645

646

647

648

649

650

651

652

653

654

655

656

657

658

659

660

661

662

663

664

665

666

667

668

669

670

671

672

673

674

675

676

Laruelle GG et al (2009) Anthropogenic perturbations of the silicon cycle at the global scale: the 1 key role of the land-ocean transition. Global Biogeochem. Cy 23, GB4031, 17 PP. doi:10.1029/2008GB003267

Le Pape O, Del Amo Y, Menesguen A, Arninot A, Quegulner B, Treguer P (1996) Resistance of a coastal ecosystem to Increasing eutrophlc conditions: the Bay of Brest (France), a semi-enclosed zone of western Europe. Cont Shelf Res 16(15):1885-1907

Meiggs D, Taillefert M (2011) The effect of riverine discharge on biogeochemical processes in estuarine sediments. Limnology and Oceanography 56: 1797-1810

Michaud E, Desrosiers G, Mermillod-Blondin F, Sundby B, Stora G (2005) The functional group approach to bioturbation: The effects of biodiffusers and gallery-diffusers of the Macomabalthica community on sediment oxygen uptake. Journal of Experimental Marine Biology and Ecology 326(1): 77-88

Middelburg JJ, Klaver G, Nieuwenhuize J, Vlug T (1995) Carbon and nitrogen cycling in intertidal sediments near Doel, Scheldt estuary. Hydrobiologia 311: 57-69

Mouret A, Anschutz P, Lecroart P, Chaillou G, Hyacinthe C, Deborde J, Jorissen FJ, Deflandre B, Schmidt S, Jouanneau JM (2009) Benthic geochemistry of manganese in the Bay of Biscay, and sediment mass accumulation rate. Geo-Marine Letters 29: 133-149

Mügler C, Rabouille C, Bombled B, Montarnal P (2012) Impact of spatial heterogeneities on oxygen consumption in sediments: Experimental observations and 2D numericalmodeling. Journal of Geochemical Exploration 112: 76-83

Nixon SW et al (1996) The fate of nitrogen and phosphorus at the land-sea margin of the North Atlantic Ocean. Biogeochemistry 35: 141-180

Pastor L, Cathalot C, Deflandre B, Viollier E, Soetaert K, Meysman FJR, Ulses C, Metzger E, Rabouille C (2011a) Modeling biogeochemical processes in sediments from the Rhône River prodelta area (NW MediterraneanSea). Biogeosciences 8: 1351-1366

Pastor L et al (2011b) Influence of the organic matter composition on benthic oxygen demand in the Rhône River prodelta (NW MediterraneanSea). Continental Shelf Research 31(9): 1008-1019 
Rabouille C, Gaillard JF (1994). Simulation of the sediment behavior during a benthic chamber deployment on the deep-sea floor. Oceanologia Acta 17: 405-416

Rabouille C, Mackenzie F, Ver LM (2001) Influence of the human perturbation on carbon, nitrogen and oxygen biogeochemical cycles in the global coastal ocean. Geochim Cosmochim Acta 65: 3615-3639

Rabouille C, Denis L, Dedieu K, Stora G, Lansard B, Grenz C (2003) Oxygen demand in coastal marine sediments: comparing in situ microelectrodes and laboratory core incubations. Journal of Experimental Marine Biology and Ecology 285-286: 49-69

Ragueneau O, Chauvaud L, Leynaert A, Thouzeau G, Paulet YM, Bonnet S, Lorrain A, Corvaisier R, Le Hir M, Jean F, J. Clavier (2002) Direct evidence of a biologically active coastal silicate pump: ecological implications. Limnology Oceanography 47:1849-1854

Raimonet M (2011) Cycle benthique du silicium dans les estuaires: observations et modélisation à différentes échelles spatio-temporelles. Ph D thesis, Université de Bretagne Occidentale, Brest, pp 179

Raimonet M, Andrieux-Loyer F, Ragueneau O, Michaud E, Kerouel R, Philippon X, Nonent M, Mémery L (in review) Strong gradient of benthic biogeochemical processes along a macrotidal temperate estuary: focus on $\mathrm{P}$ and Si cycles. Biogeochemistry

Resing JA, Mottl MJ (1992) Determination of manganese in seawater using flow injection analysis with on-line preconcentration and spectrophotometric detection. Anal. Chem. 64(22): 2682-2687

Revsbech NP, Jorgensen BB (1986) Microelectrodes: their use in microbial ecology. Adv Microb Ecol 9: 293352

Revsbech NP (1989) An oxygen microsensor with a guard cathode. Limnol Oceanogr 34: 474-478

Ruiz-Fernández AC, Hillaire-Marcel C, Ghaleb B, Soto-Jiménez M, Páez-Osuna, F (2002) Recent sedimentary history of anthropogenic impacts on the Culiacan River Estuary, northwestern Mexico: geochemical evidence from organic matter and nutrients. Environ. Pollut. 118: 365-377

Sarradin PM, Le Bris N, Le Gall C, Rodier P (2005) Fe analysis by the ferrozine method: Adaptation to fia towards in situ analysis in hydrothermal environment. Talanta 66(5):1131-1138 
713 Seeberg-Elverfeldt J, Schlüter M, Feseker Tomas, Kölling M (2005) Rhizon sampling of porewaters near the

714 sediment-water interface of aquatic systems. Limnol Oceanogr: Methods 3: 361-371

Seitzinger SP (1988) Denitrification in freshwater and coastal marine ecosystem: ecological and geochemical significance. Limnol. Oceanogr. 33: 702-724

718

Sweerts JP, De Beer D (1989) Microelectrode measurements of nitrate gradients in the littoral and profundal sediments of a meso-eutrophic lake (lake Vechten, the Netherlands). App Envir Microb 55: 754-757

Tabatabai MA (1974) A rapid method for determination of sulphate in water samples. Environmental Letters

Tesi T, Miserocchi S, Goni MA, Langone L, Boldrin A, Turchetto M (2007) Organic matter origin and distribution in suspended particulate materials and surficial sediments from the western Adriatic Sea (Italy). Estuar. Coast. Shelf S 73: 431-446

Thamdrup B, Wurgler Hansen J, Barker Jorgensen B (1998) Temperature dependance of aerobic respiration in a costal sediment. FEMS Microiology Ecology 25: 189-200 (2007) Spatial and temporal variability of benthic biogeochemical fluxes associated with macrophytic and macrofaunal distributions in the Thau lagoon (France). Estuarine, Coastal and Shelf Science 72(3): $432-446$ 


\section{Tables}

Table 1 Environmental parameters (temperature $\mathrm{T}\left({ }^{\circ} \mathrm{C}\right)$, salinity S, depth $\mathrm{D}(\mathrm{m})$, river discharge $\mathrm{Q}\left(\mathrm{m}^{3} \mathrm{~s}^{-1}\right)$, and bottom water $\mathrm{O}_{2}$ concentration $\mathrm{O}_{2 \mathrm{bw}}(\mu \mathrm{M})$ ) at each station and season during benthic sampling

\begin{tabular}{|c|c|c|c|c|c|}
\hline Station & $\mathrm{T}\left({ }^{\circ} \mathrm{C}\right)$ & $S$ & $\mathrm{D}(\mathrm{m})$ & $\mathrm{Q}(\mathrm{m} 3 \mathrm{~s}-1)$ & $\mathrm{O}_{2 \mathrm{bw}}(\mu \mathrm{M})$ \\
\hline \multicolumn{6}{|c|}{ February } \\
\hline E1 & 8 & 0 & 1 & 18.5 & 377 \\
\hline E2 & 7.6 & 17.5 & 2 & 15.7 & 310 \\
\hline E3 & 8.2 & 29 & 3.5 & 14.5 & 297 \\
\hline $\mathrm{A} 1$ & 7.7 & 0 & 2.5 & 64.6 & 415 \\
\hline $\mathrm{A} 2$ & 7.4 & 13.7 & 3 & 54.1 & 352 \\
\hline A3 & 8 & 20 & 1.75 & 49.7 & 293 \\
\hline \multicolumn{6}{|c|}{ May } \\
\hline E1 & 12.3 & 0 & 1 & 4.69 & 330 \\
\hline E2 & 13.4 & 21.7 & 1.5 & 4.33 & 273 \\
\hline E3 & 12.8 & 33.5 & 6 & 4.24 & 277 \\
\hline $\mathrm{A} 1$ & 14.4 & 0 & 2 & 10.4 & 314 \\
\hline $\mathrm{A} 2$ & 14 & 22.5 & 3 & 9.95 & 277 \\
\hline A3 & 13.5 & 24.6 & 2 & 10.7 & 282 \\
\hline \multicolumn{6}{|c|}{ July } \\
\hline E1 & 16.7 & 0 & 0.5 & 2.79 & 304 \\
\hline E2 & 16.7 & 12.2 & 1 & 2.48 & 213 \\
\hline E3 & 17.7 & 33.5 & 6 & 1.77 & 225 \\
\hline $\mathrm{A} 1$ & 19.7 & 0 & 0.5 & 4.24 & 292 \\
\hline $\mathrm{A} 2$ & 19.5 & 27.5 & 1.5 & 5.01 & 202 \\
\hline A3 & 19.1 & 30.9 & 3 & 3.59 & 345 \\
\hline \multicolumn{6}{|c|}{ October } \\
\hline E1 & 15 & 0.8 & 0.5 & 1.45 & 294 \\
\hline E2 & 15.1 & 29.6 & 1.2 & 1.45 & 204 \\
\hline E3 & 15.3 & 34.2 & 8 & 1.42 & 217 \\
\hline $\mathrm{A} 1$ & 14.2 & 8.7 & 1 & 3.67 & 278 \\
\hline $\mathrm{A} 2$ & 15.5 & 29.9 & 1 & 3.47 & 225 \\
\hline A3 & 15 & 33 & 2.5 & 4.91 & 228 \\
\hline
\end{tabular}




\section{Figures}

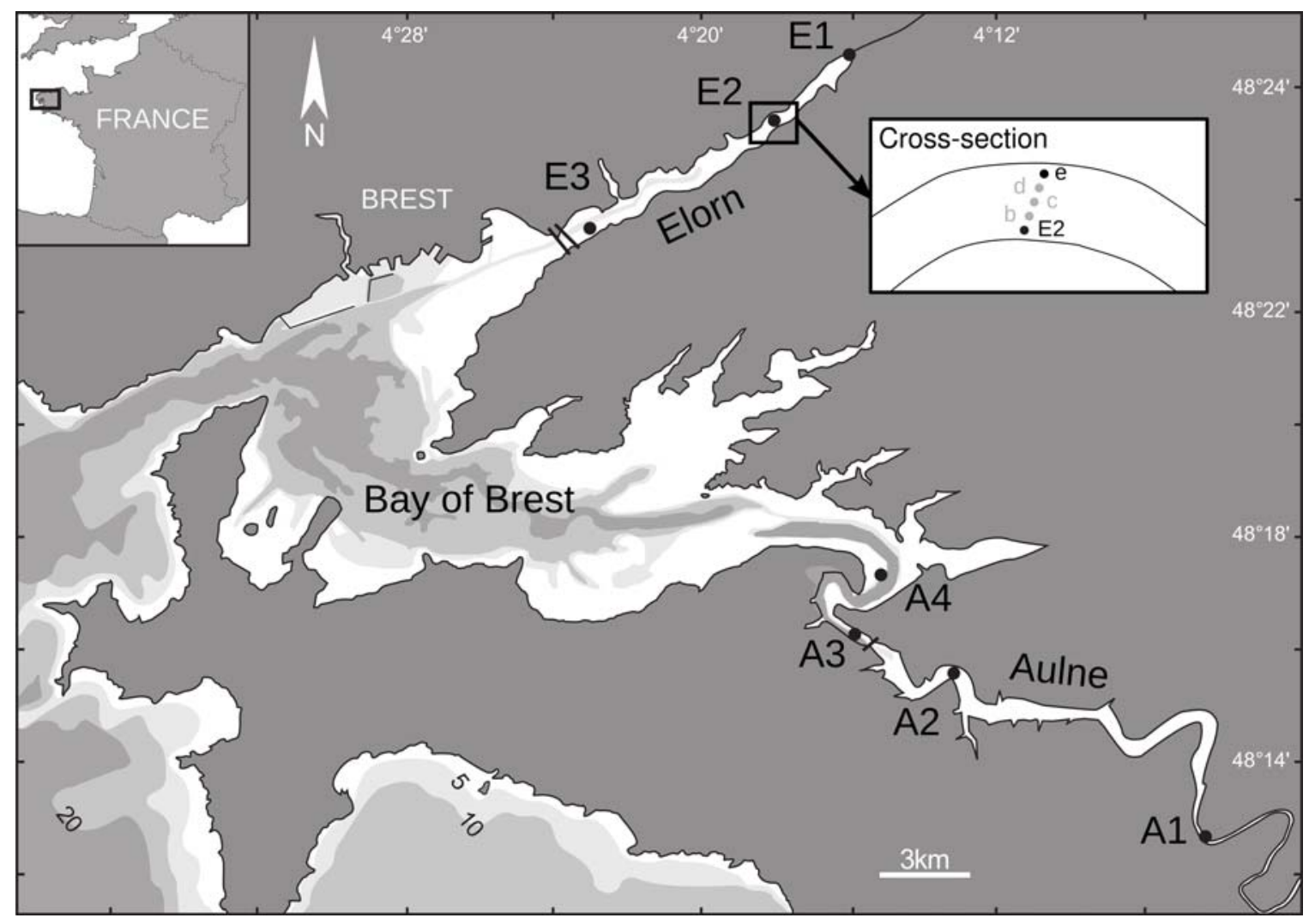

Fig.1 Study area and location of stations sampled in February, May, July and October 2009 along the Elorn and Aulne estuaries 

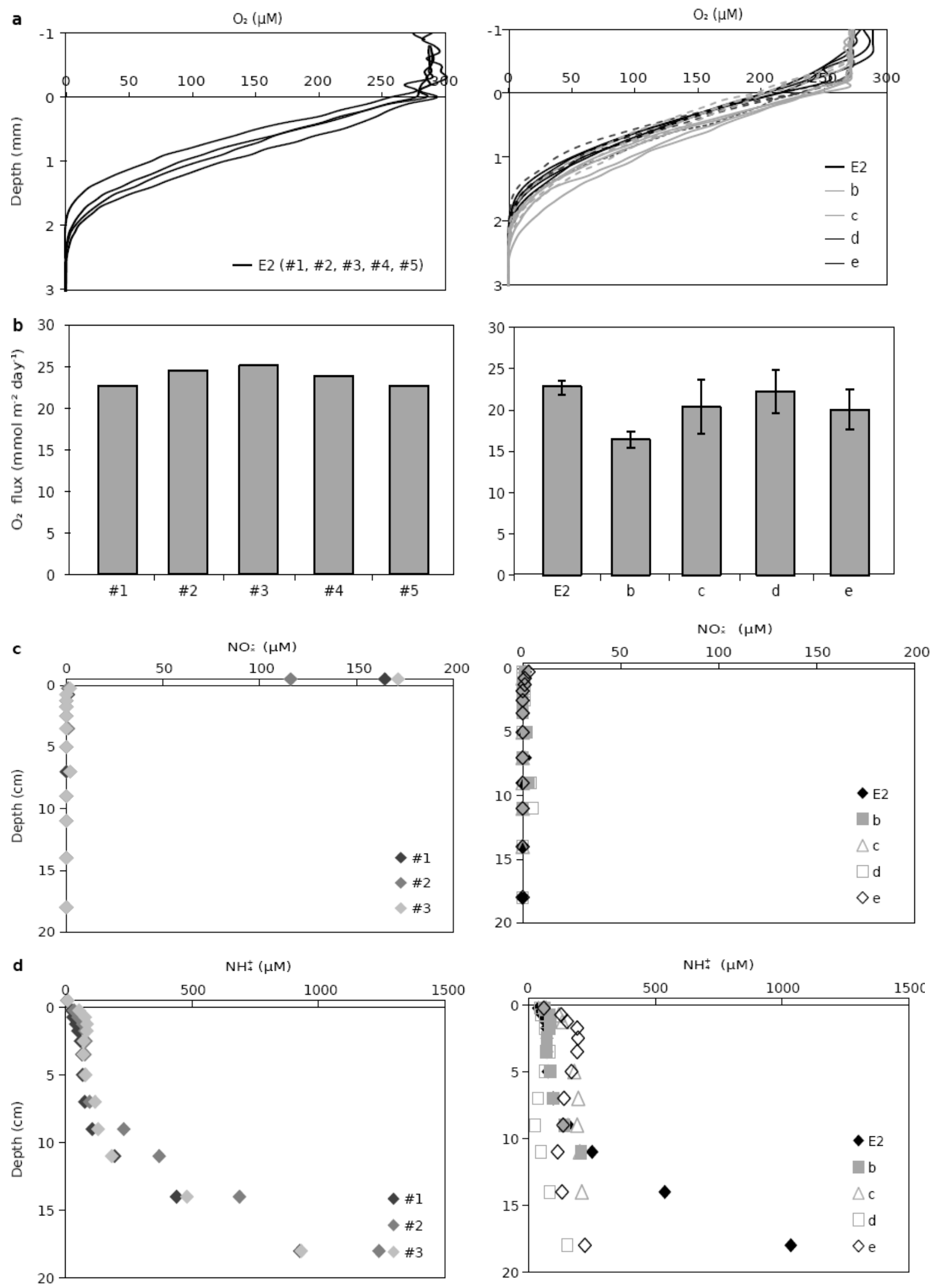

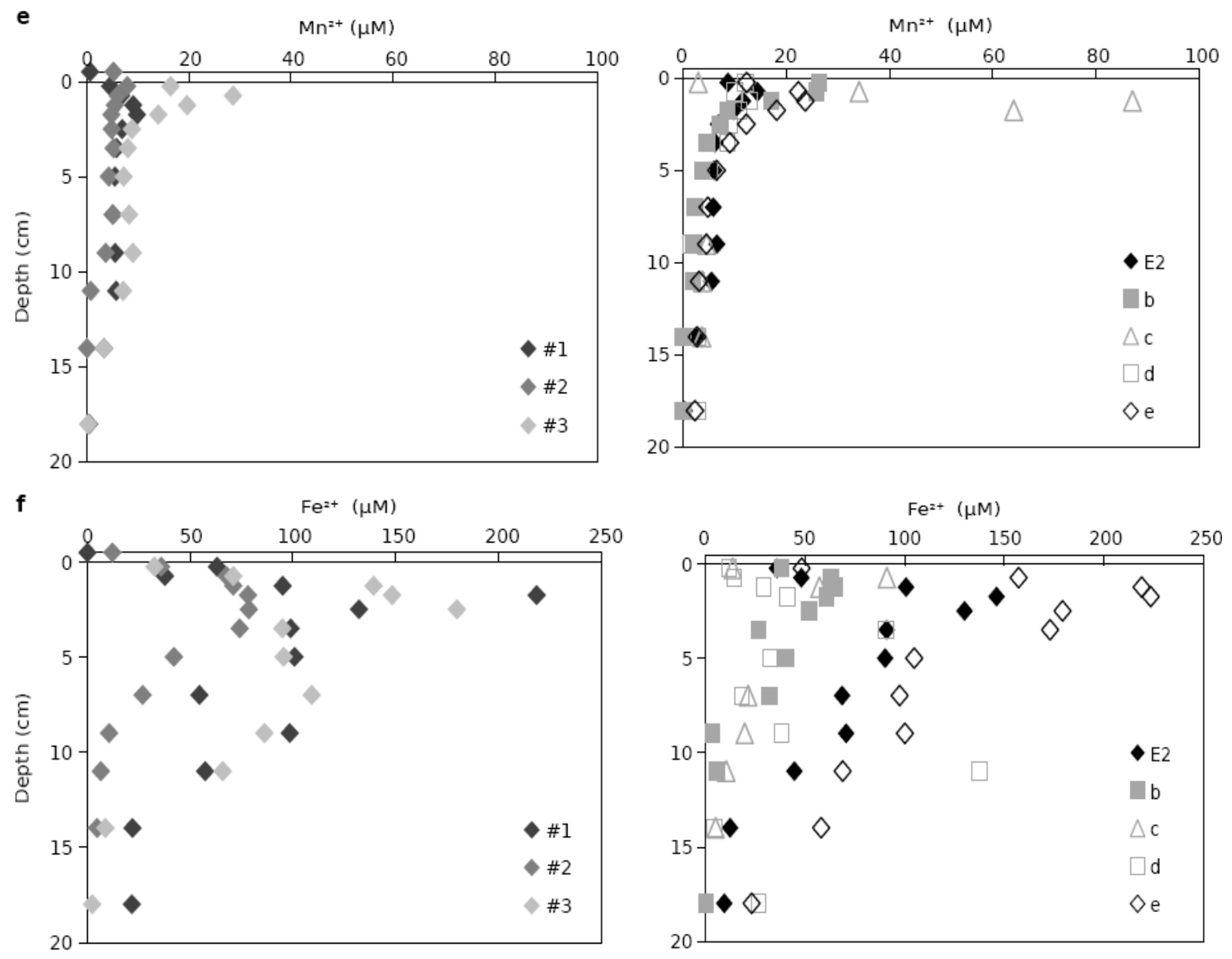

Fig.2 $\mathrm{O}_{2}$ concentrations (a), $\mathrm{O}_{2}$ fluxes (b), $\mathrm{NO}_{\mathrm{x}}{ }^{-}$(c), $\mathrm{NH}_{4}{ }^{+}$(d), $\mathrm{Fe}^{2+}$ (e), and $\mathrm{Mn}^{2+}$ concentrations (f) in pore waters at station E2 (left panels) and in a transversal cross-estuarine section (right panels) in May 2009 
$\mathbf{a}$
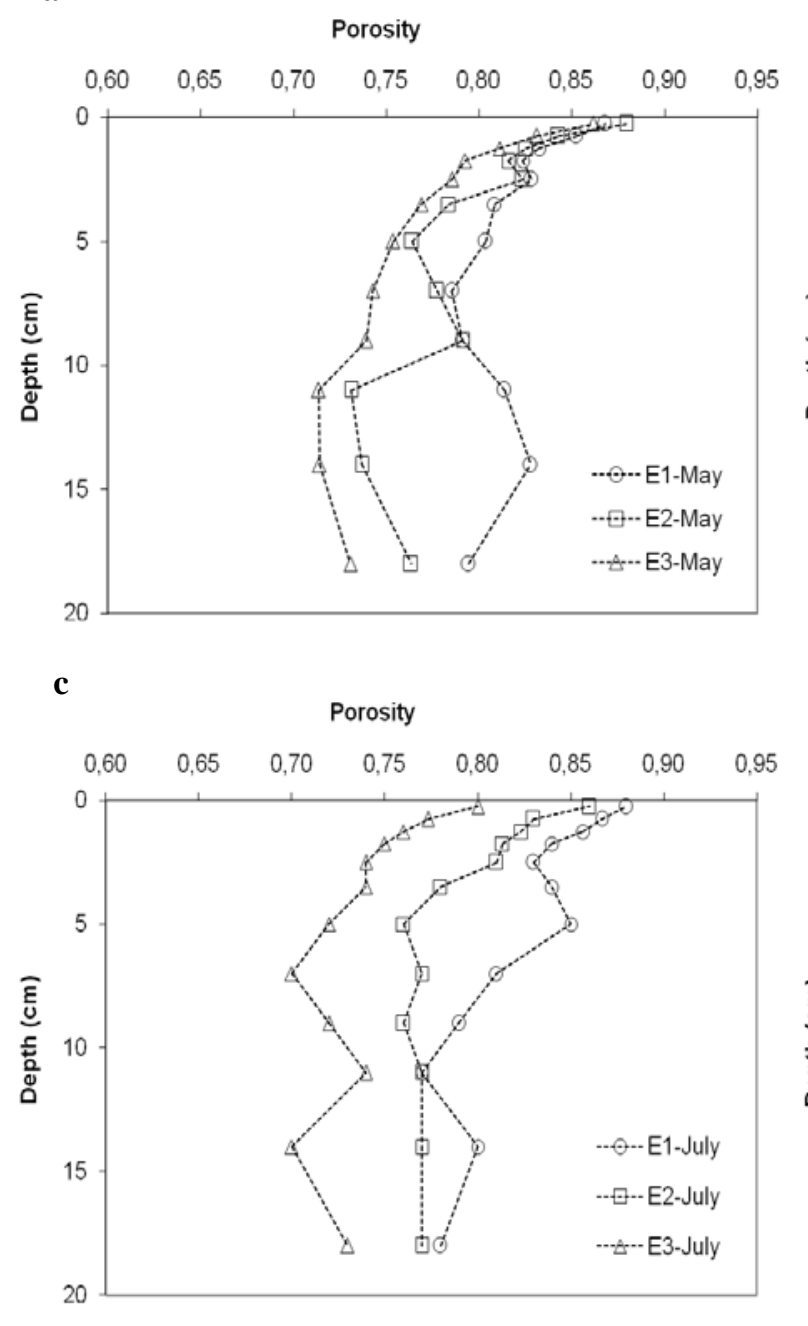

$\mathbf{e}$

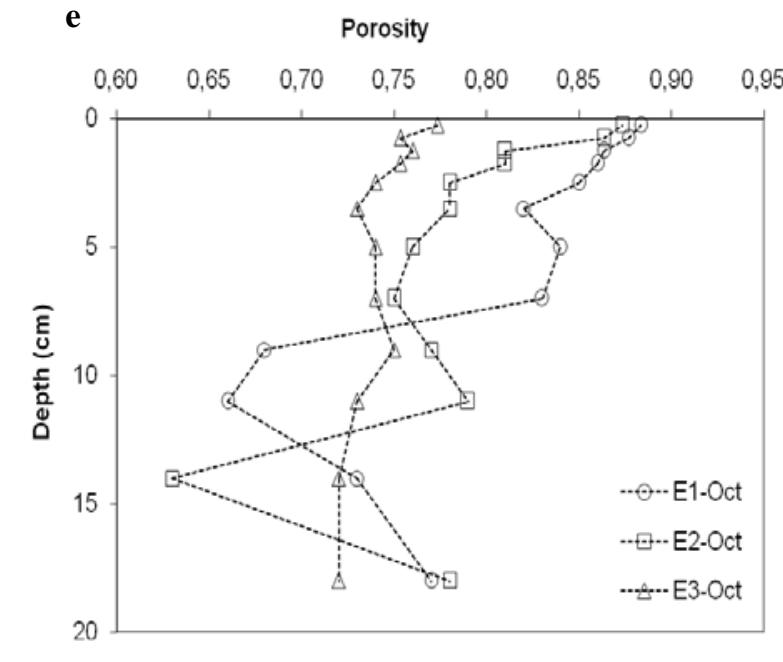

b

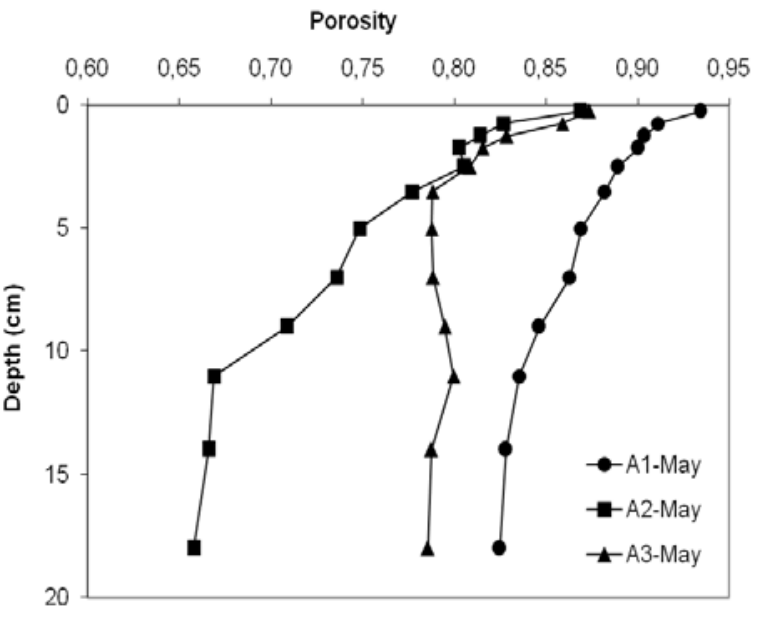

d

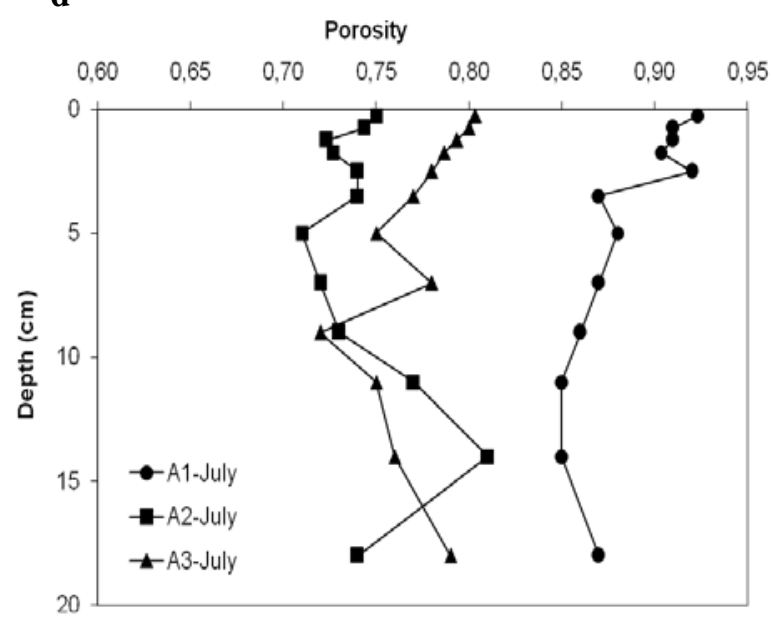

\begin{tabular}{llllllll} 
f & \multicolumn{7}{c}{ Porosity } \\
0,60 & 0,65 & 0,70 & 0,75 & 0,80 & 0,85 & 0,90 & 0,95
\end{tabular}

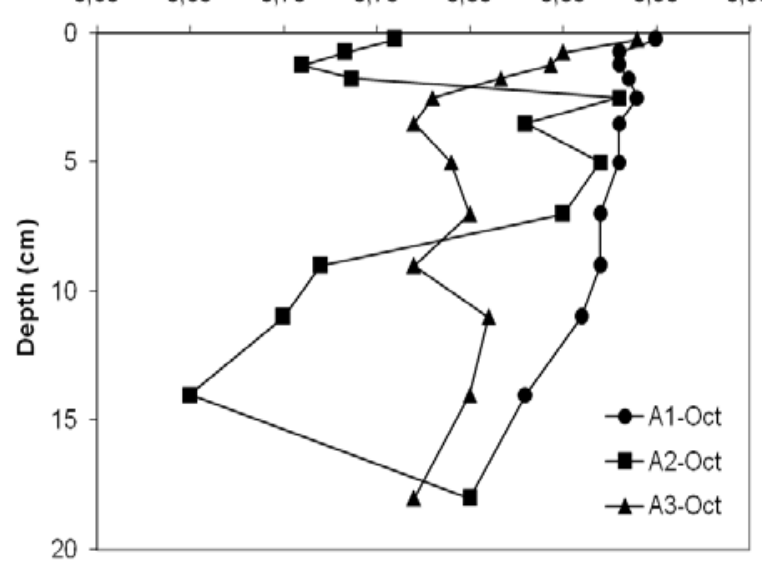

Fig.3 Porosity profiles over depth in May (a, b); in July (c, d) and in October (e, f). Left and right panels represent the Elorn and Aulne Estuary, respectively 
a

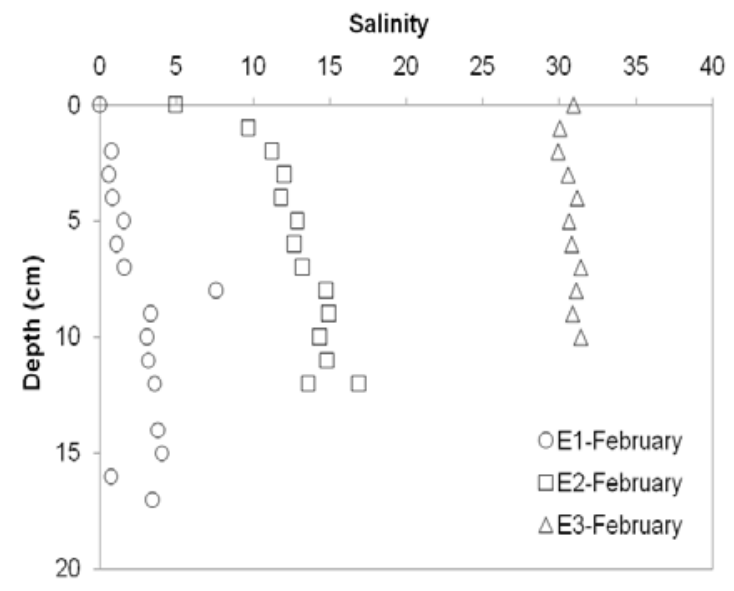

C

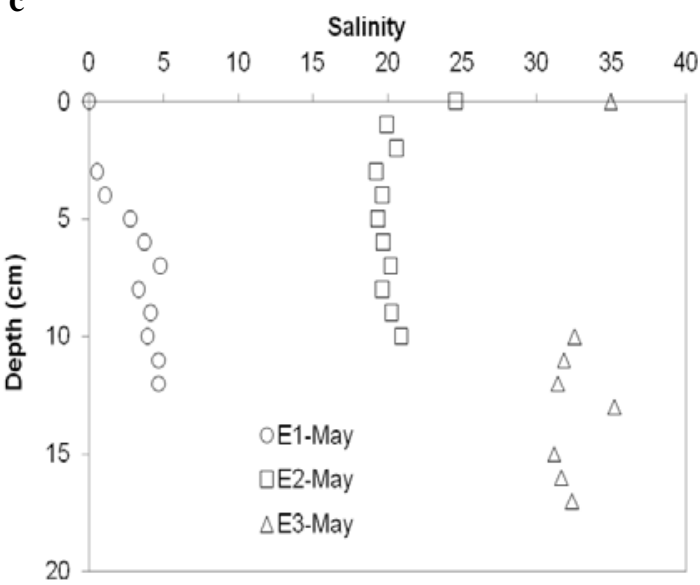

b

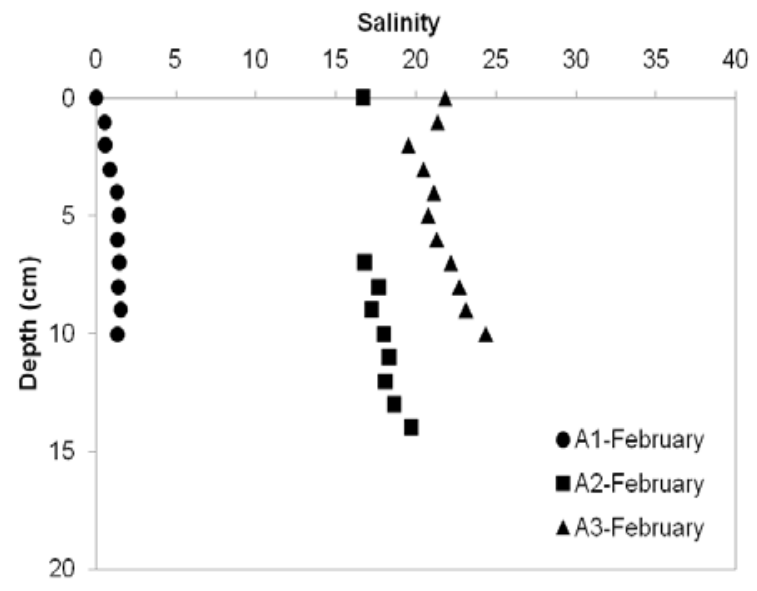

d

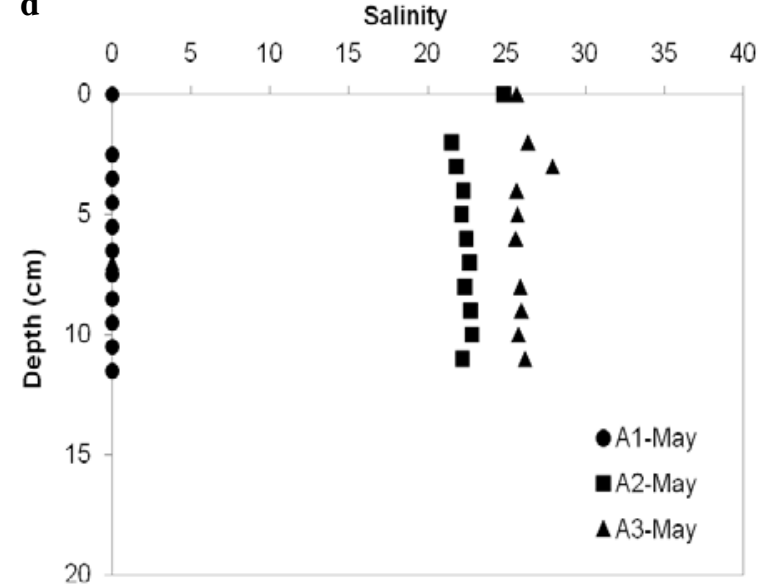

Fig.4 Salinity profiles over depth in February (a, b); in May (c, d). Left and right panels represent the Elorn and Aulne Estuary, respectively. 
a

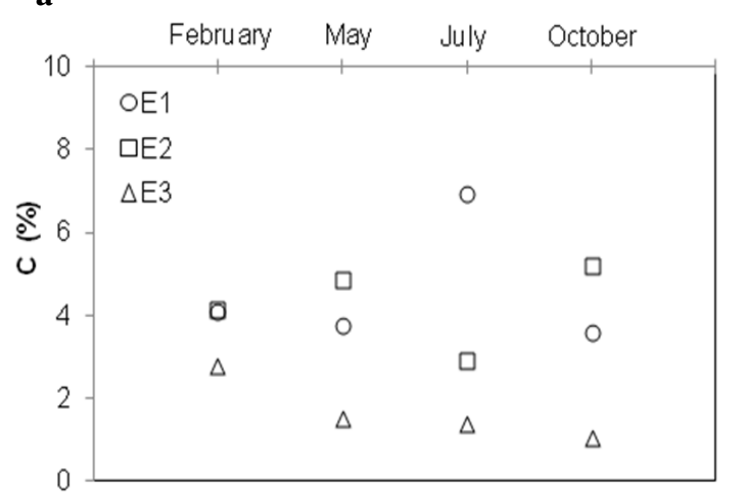

C

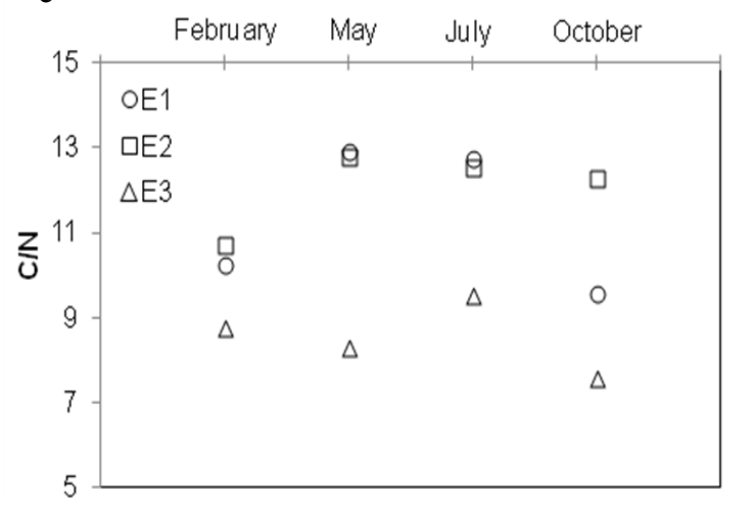

e

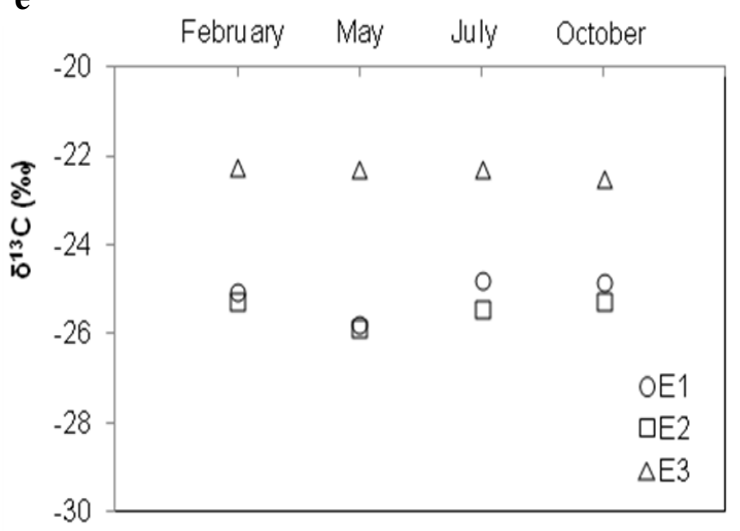

b

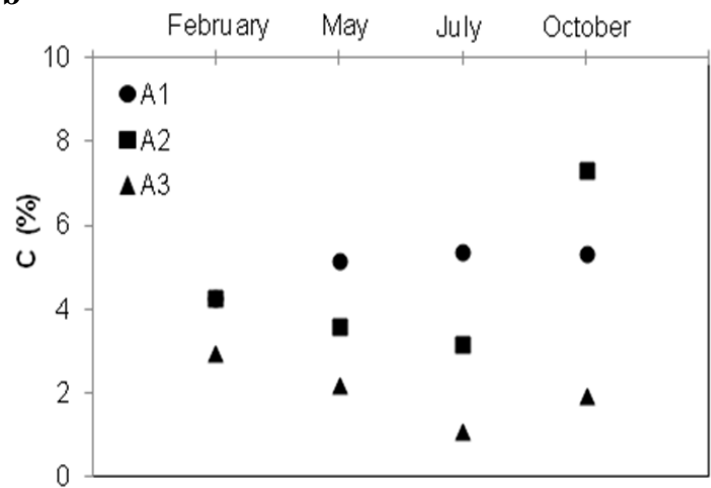

d

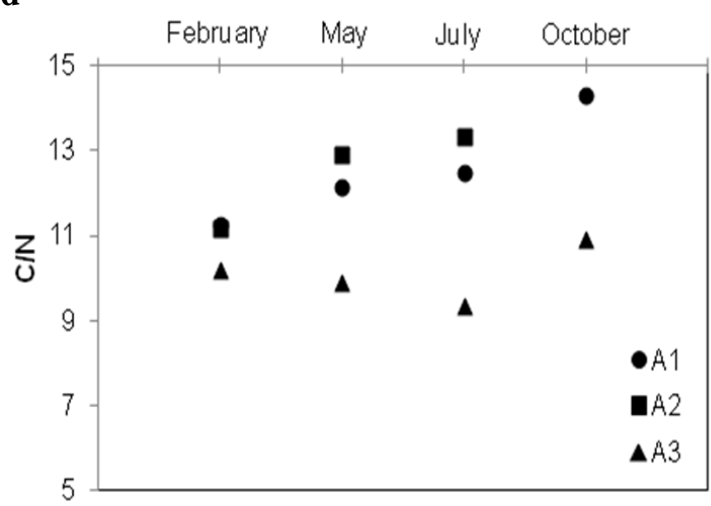

f

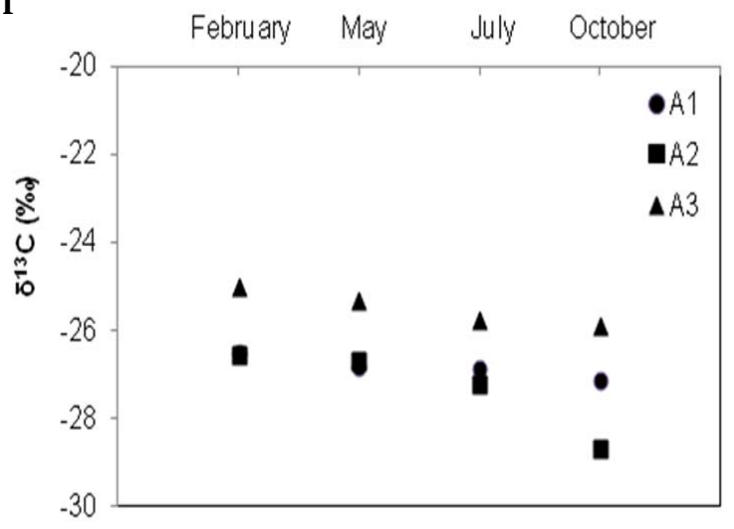

Fig.5 Organic carbon contents (a) and (b), Carbon to Nitrogen atomic ratio (c) and (d), isotopic of carbon (e) and (f) measured on the top layer for Elorn and Aulne Estuary respectively, on level 0-0.5 cm in February and on 50/50 mix of level 0-0.5 and 2-3 cm in other cruises May, July and October 
a
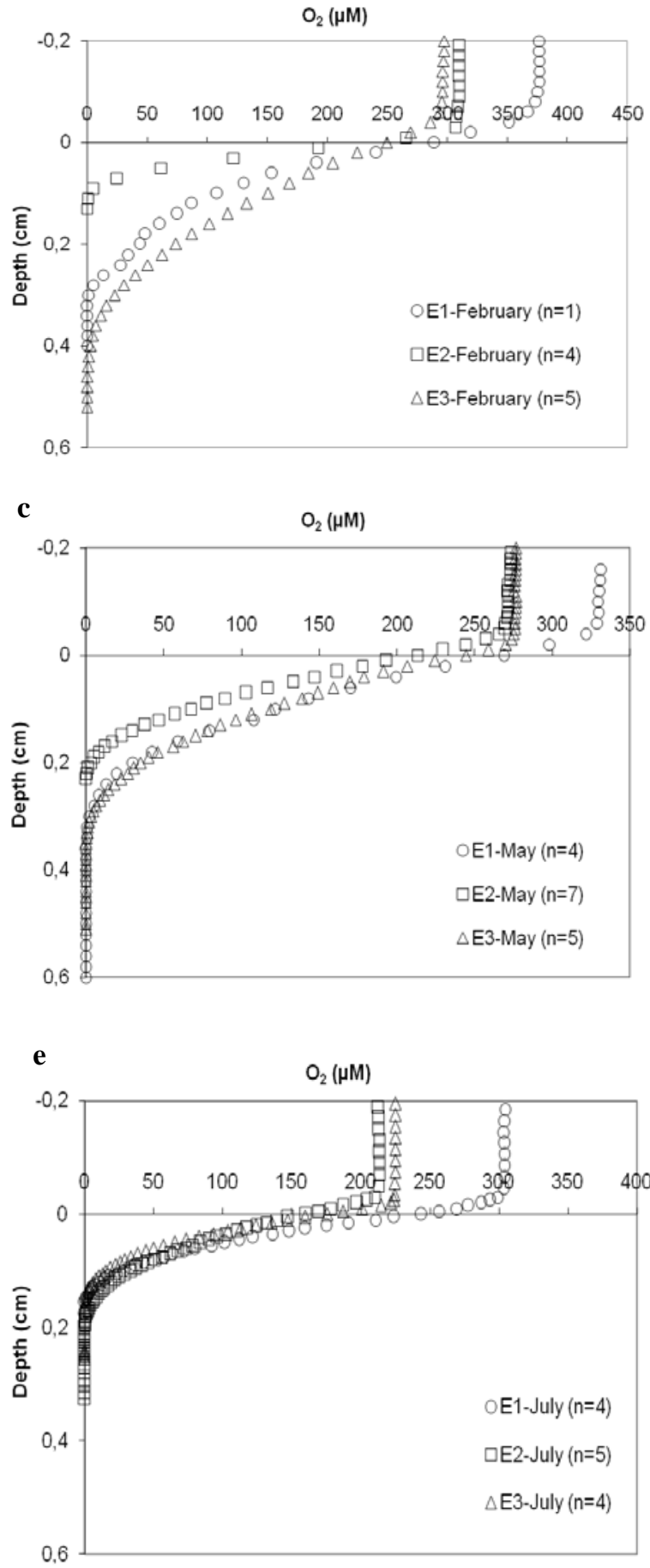

b
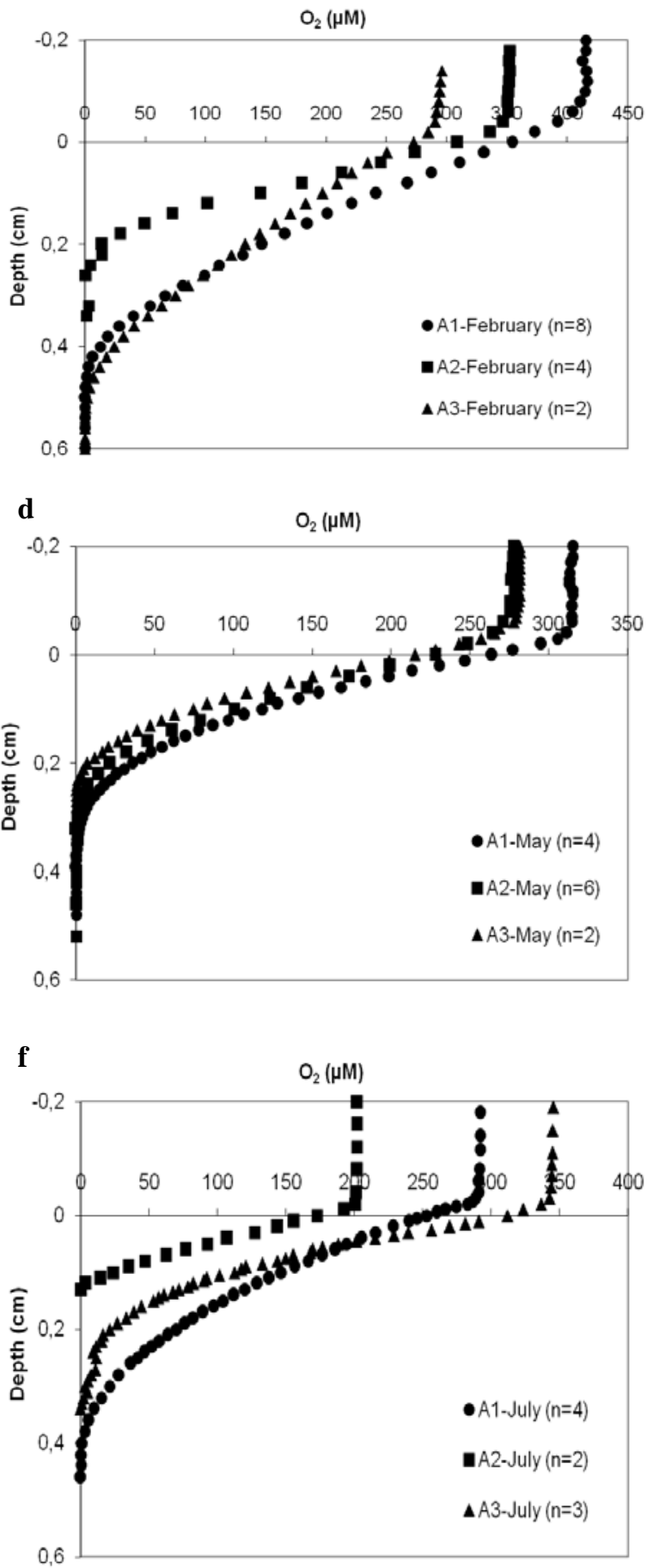
g

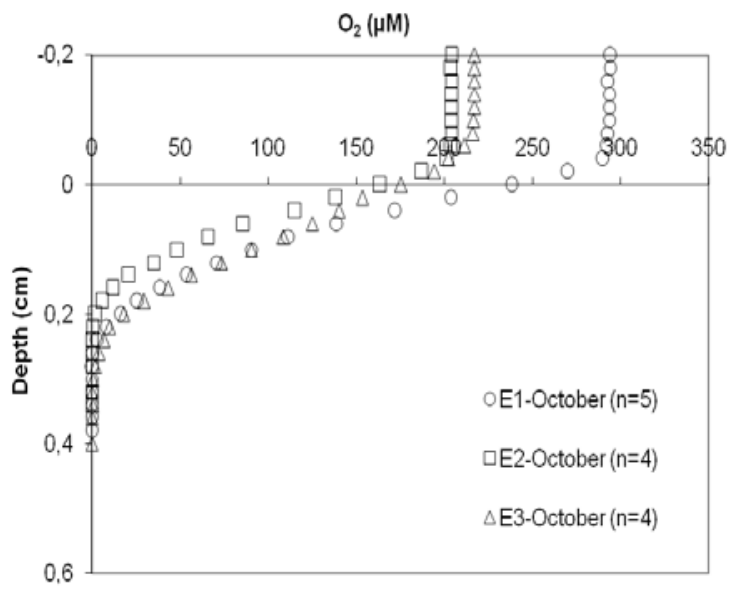

i

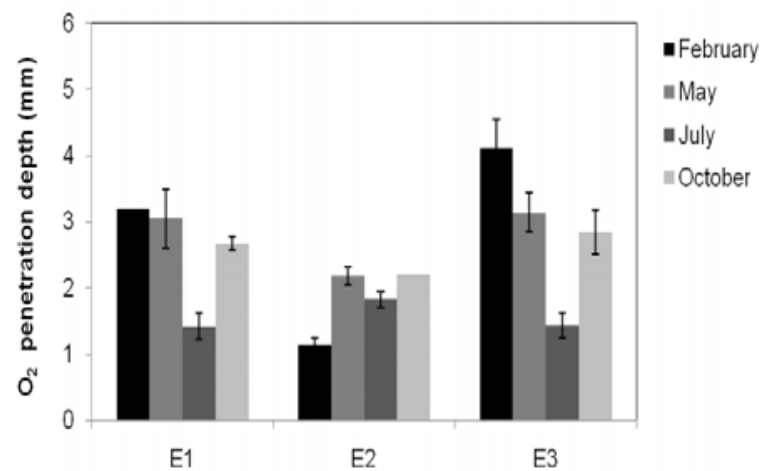

h

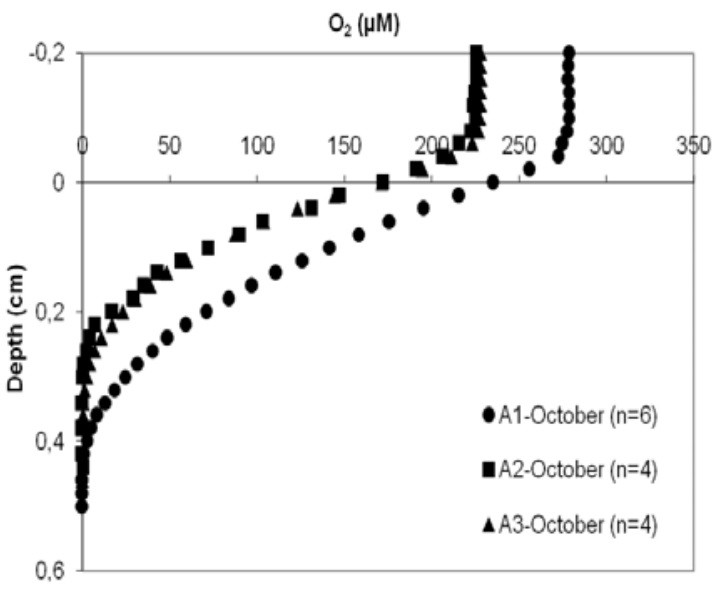

j

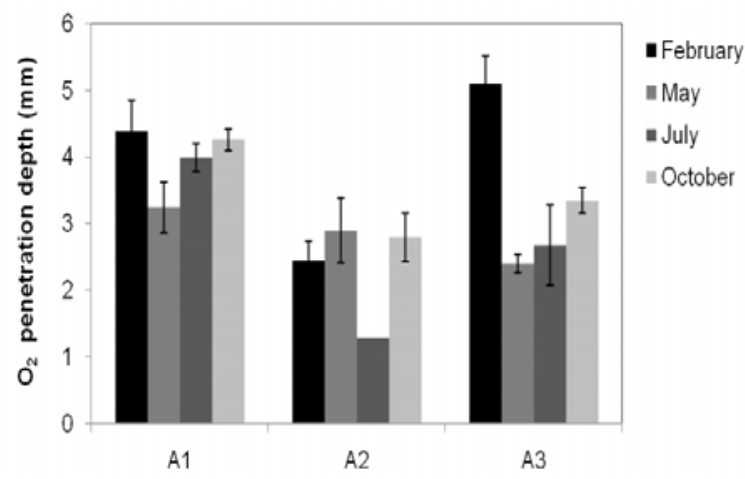

Fig.6 Average oxygen profiles over depth in February (a, b); in May (c, d); in July (e, f) and in October (g, h); oxygen penetration depth at all seasons February, May, July and October (i, j). Left and right panels represent the Elorn and Aulne Estuary, respectively 


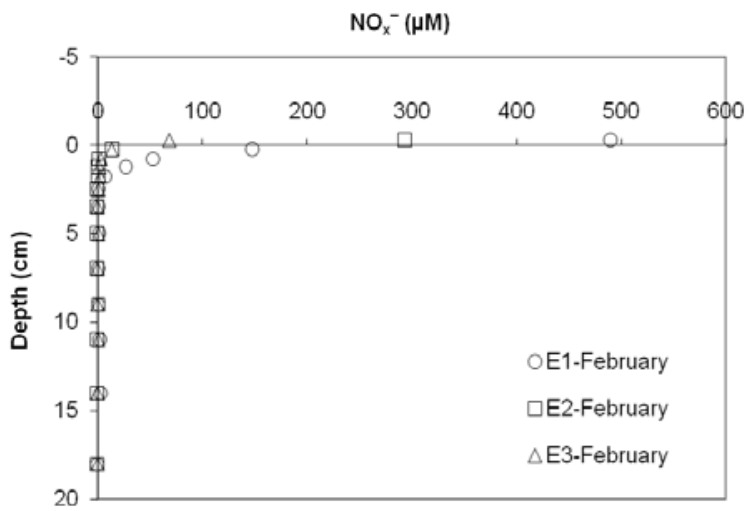

C

$\mathrm{NH}_{4}{ }^{+}(\mu \mathrm{M})$

b
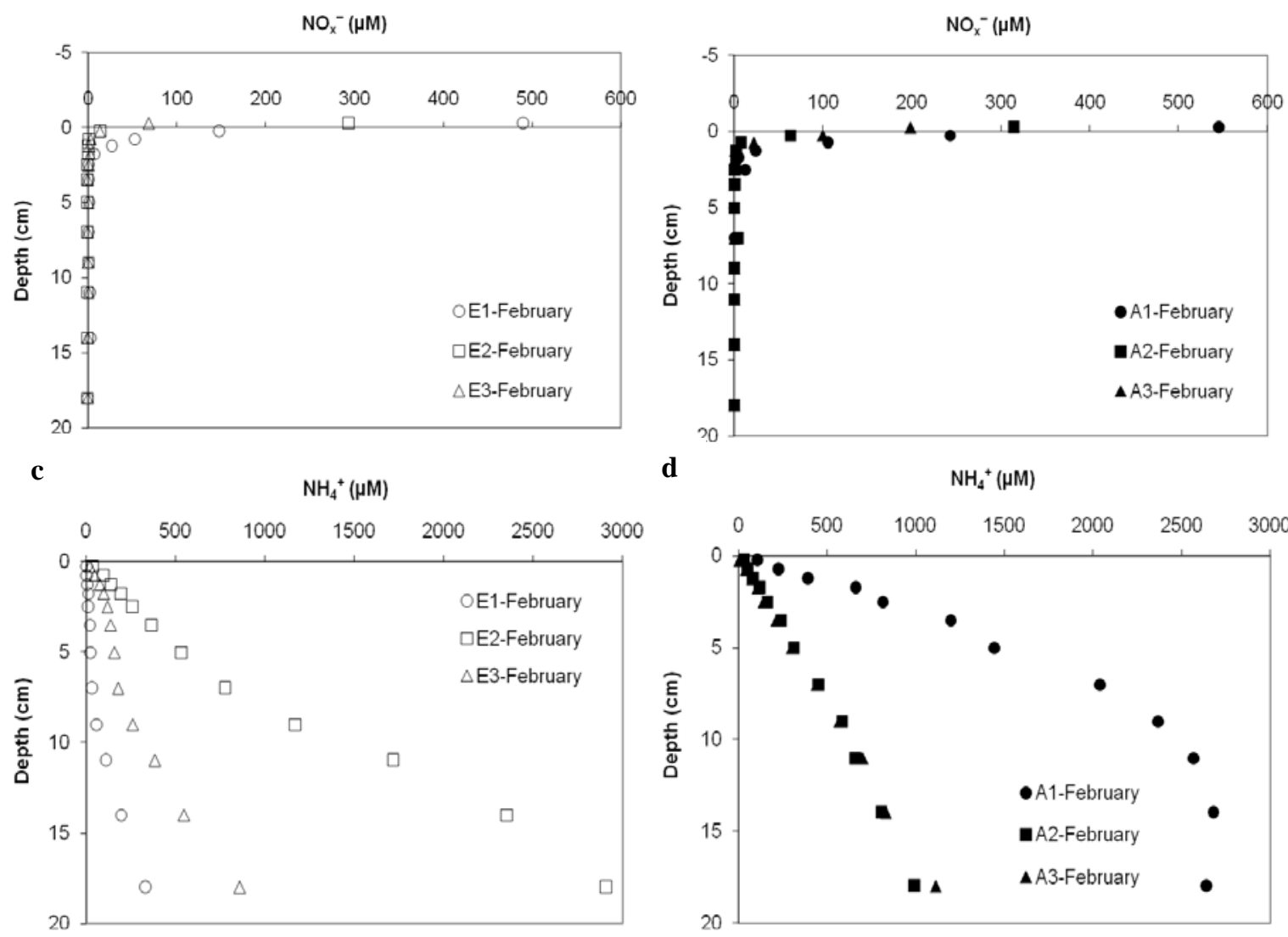

e

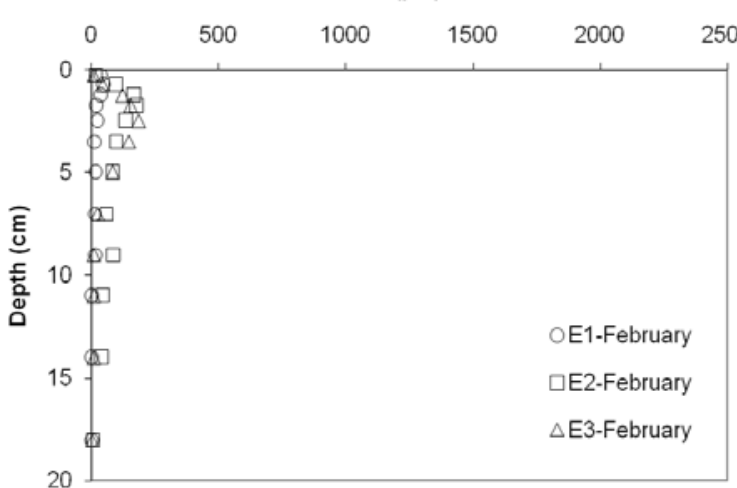

g

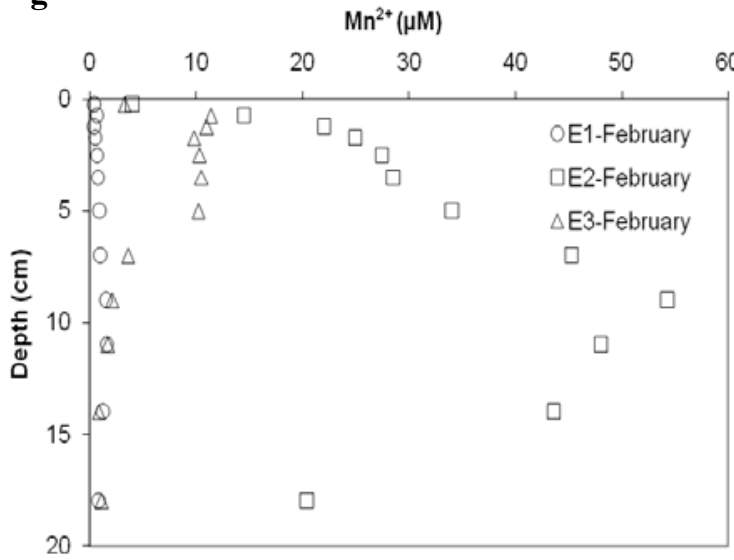

f $\mathrm{Fe}^{2+}(\mu \mathrm{M})$

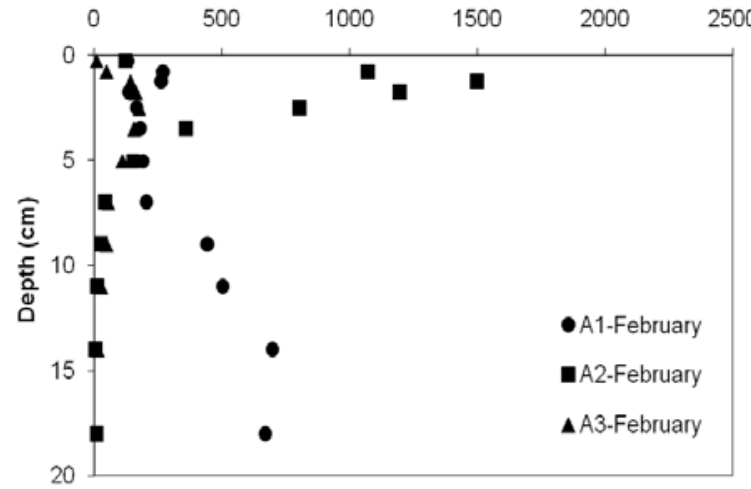

h

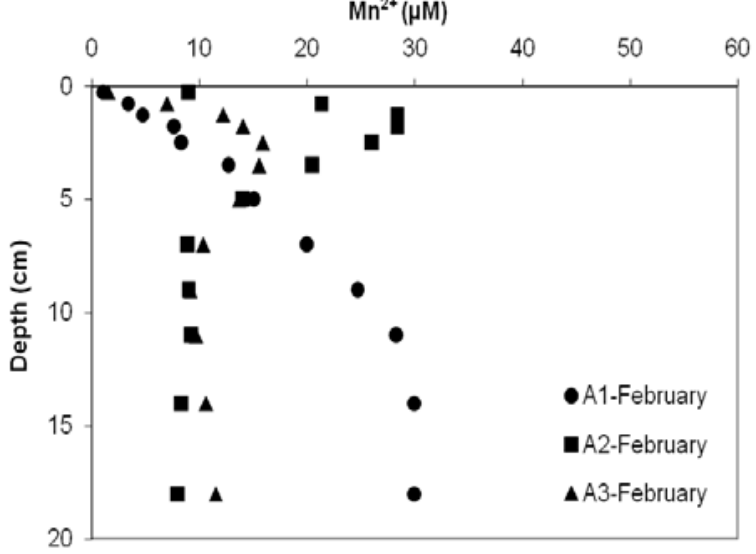




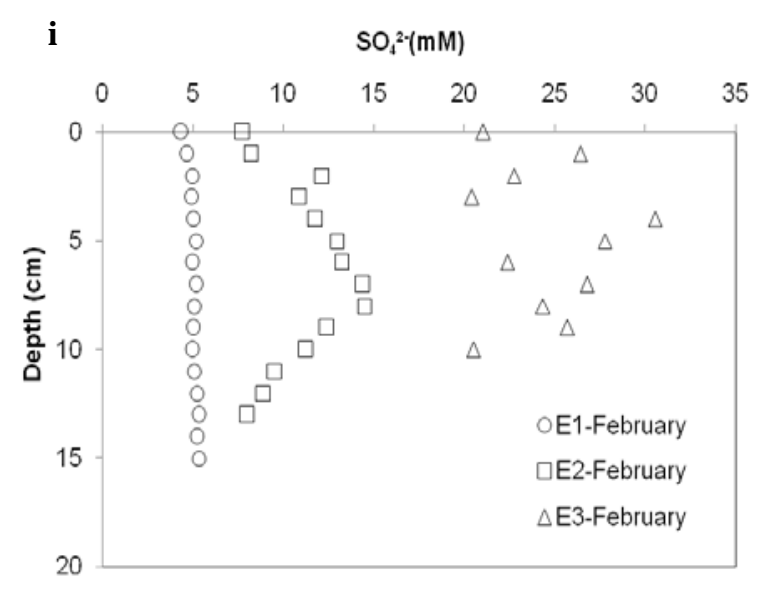

j
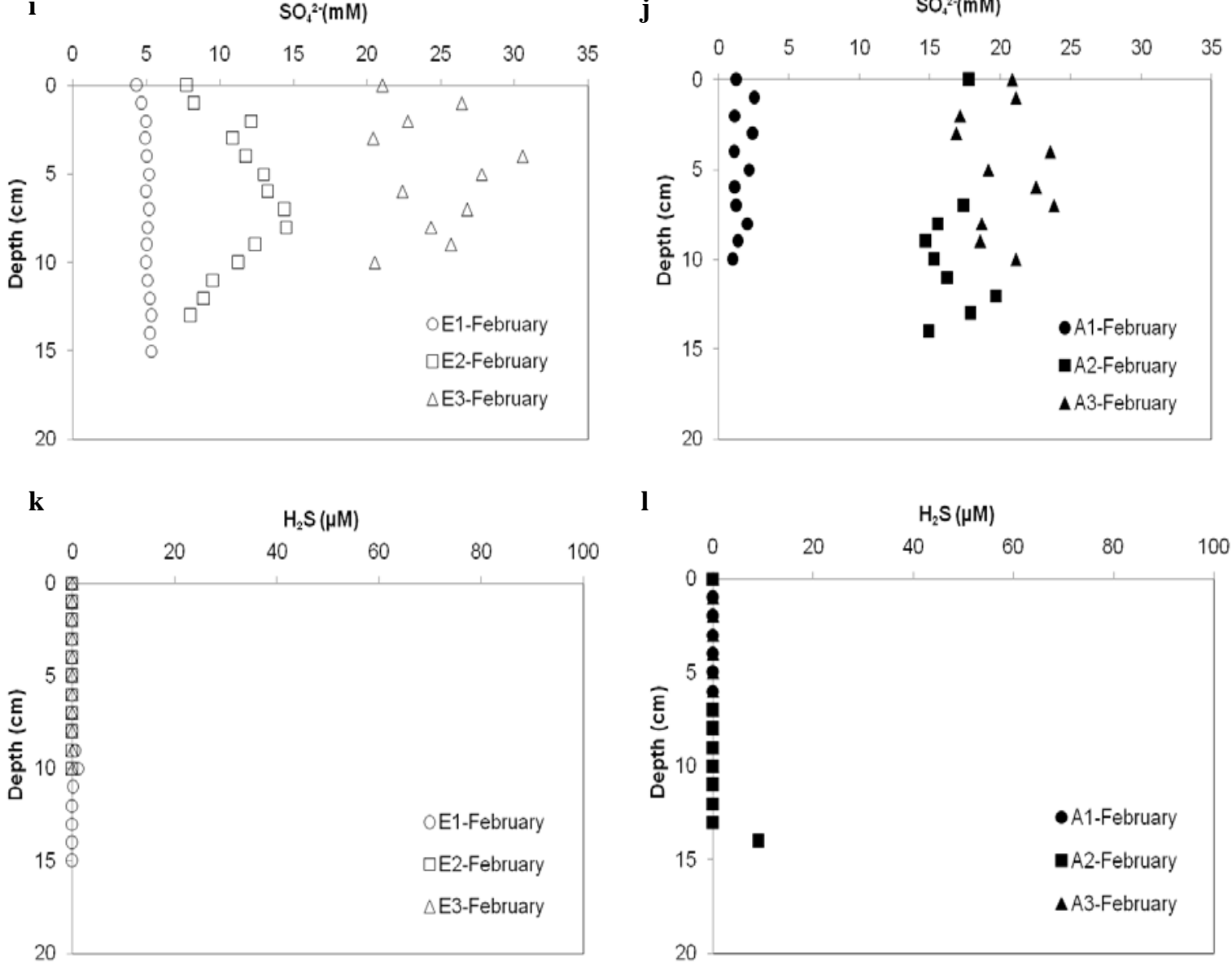

1
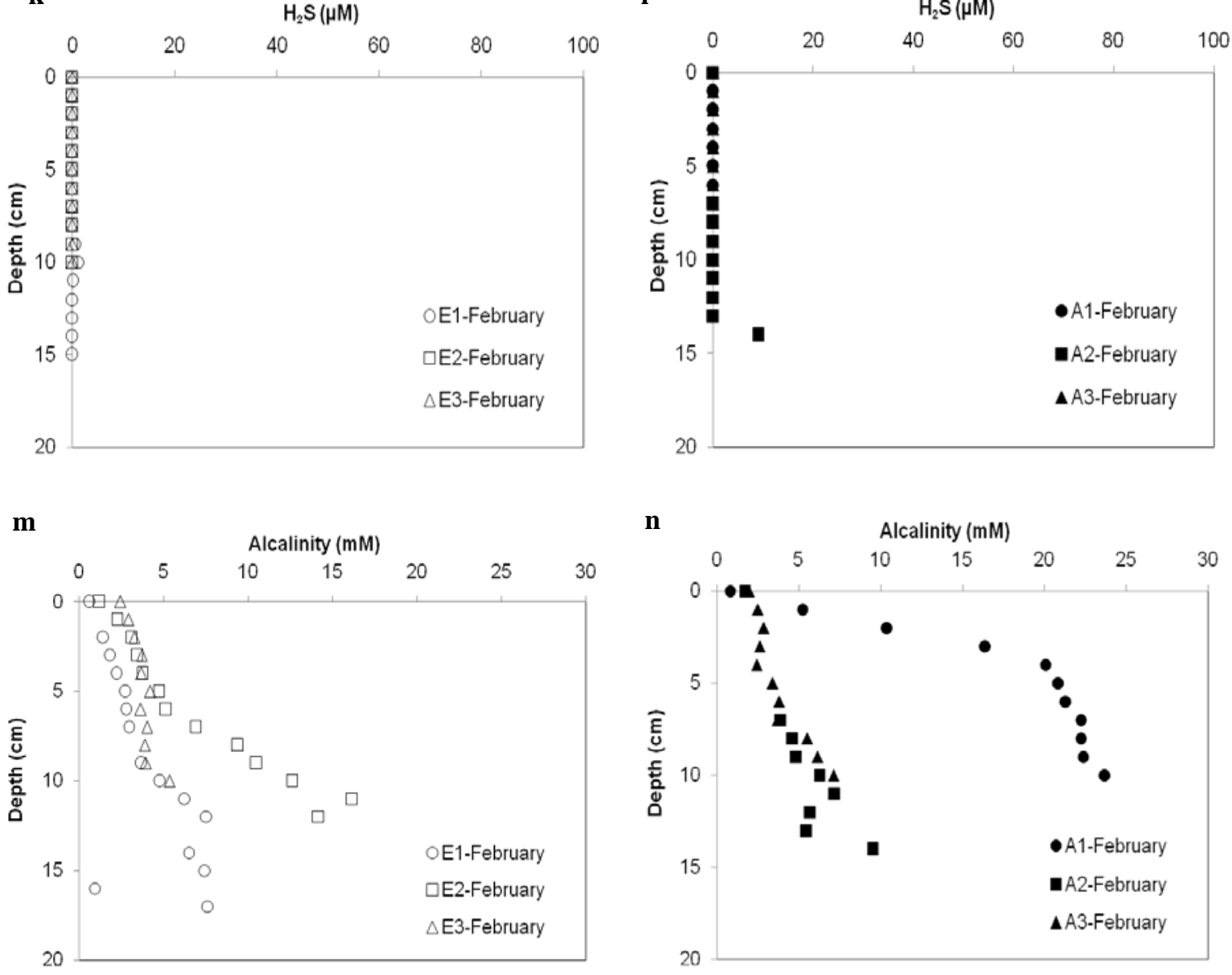

Fig.7 Nitrogen profiles over depth (a, b), ammonium profiles over depth (c, d), iron profiles over depth (e, f), manganese profiles over depth (g, h), sulfate profiles over depth (i, j), sulfide profiles over depth (k, l), alcalinity profiles over depth $(\mathrm{m}, \mathrm{n})$. Left and right panels represent the Elorn and Aulne Estuary, respectively, in February 
a

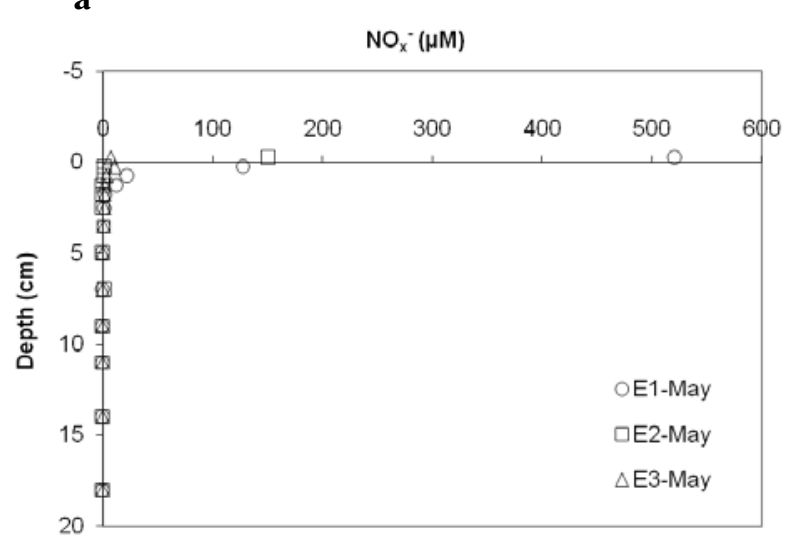

C

$\mathrm{NH}_{4}{ }^{2+}(\mu \mathrm{M})$

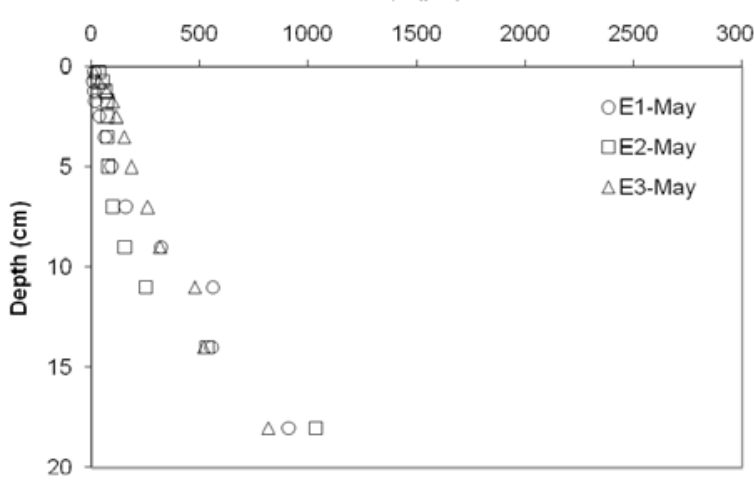

$$
\text { e }
$$
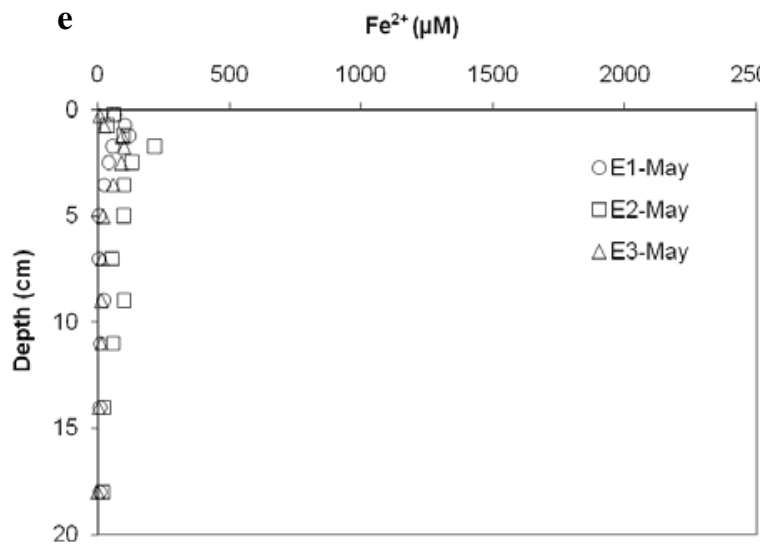

g

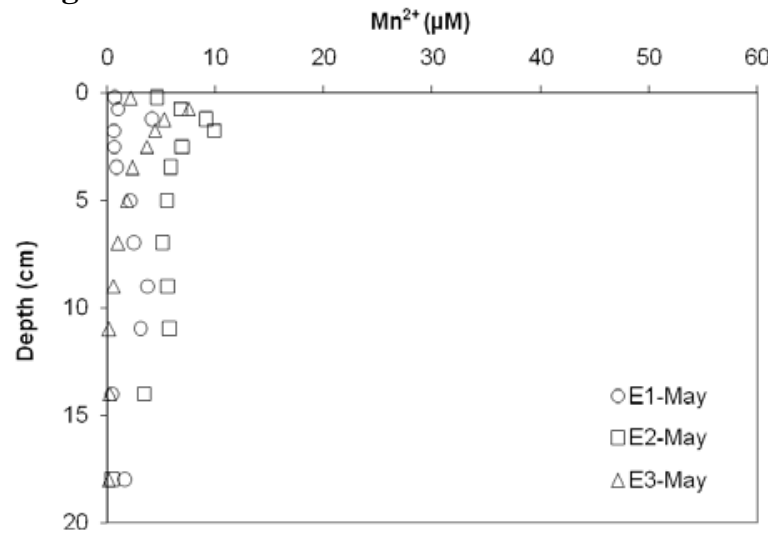

b

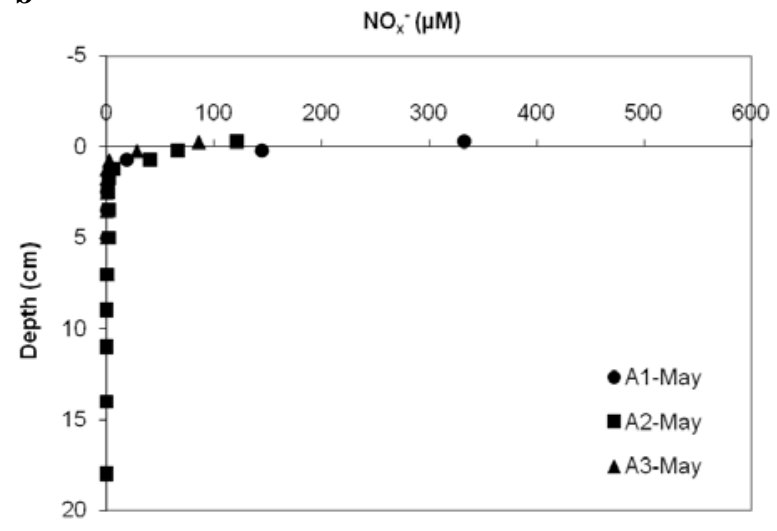

d

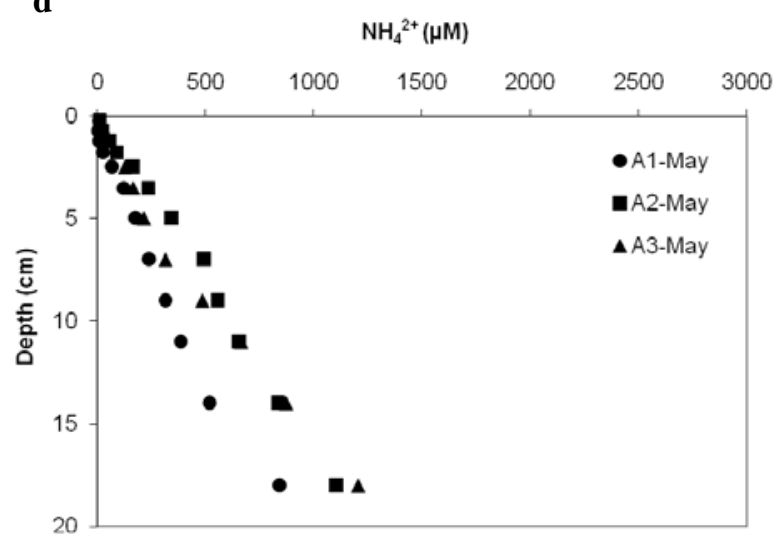

f

$\mathrm{Fe}^{2+}(\mu \mathrm{M})$

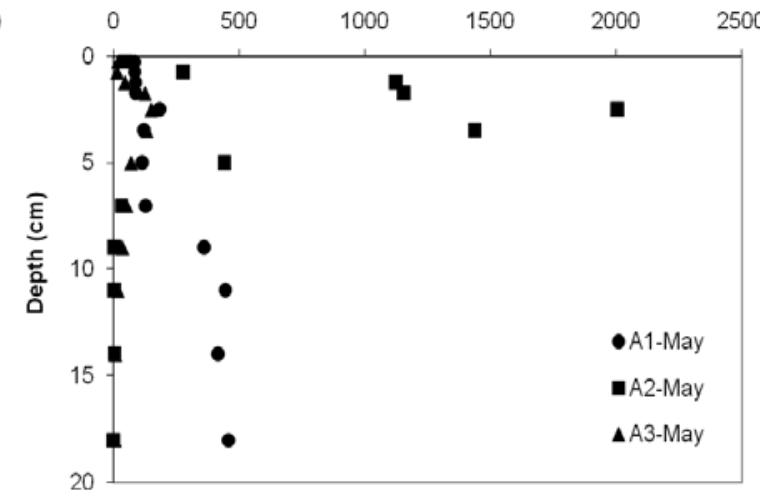

h $\mathrm{Mn}^{2+}(\mu \mathrm{M})$

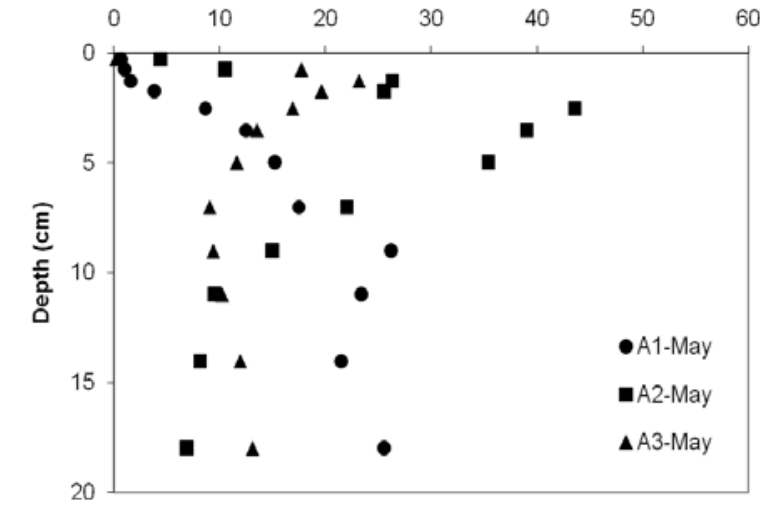


i

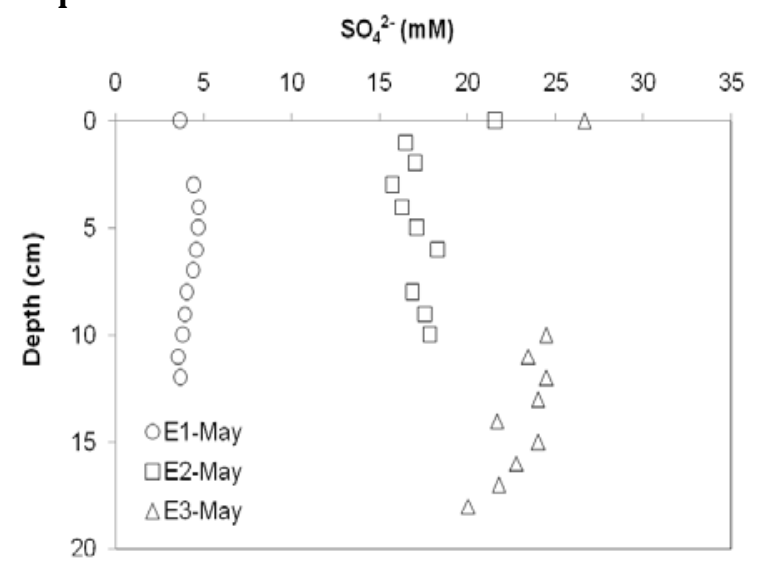

$\mathbf{k}$

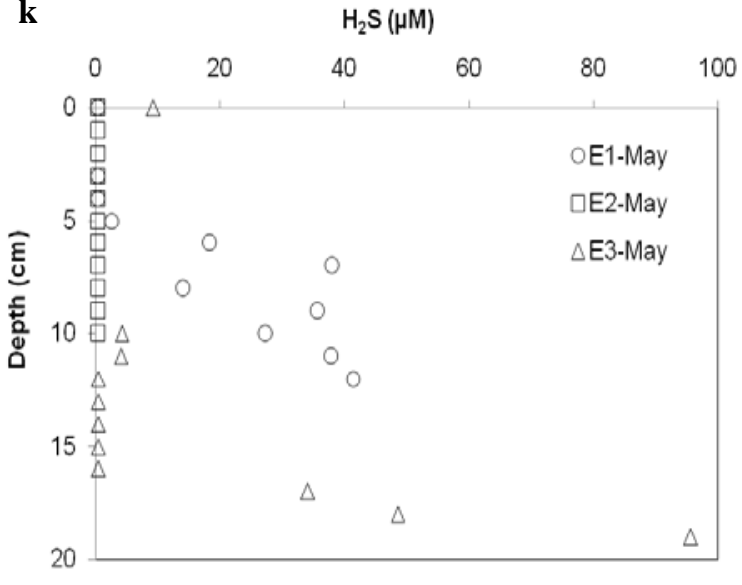

m

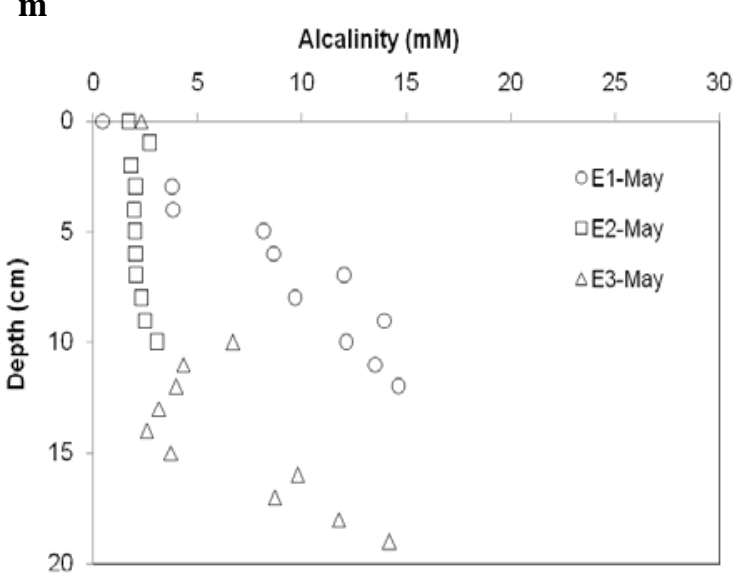

j

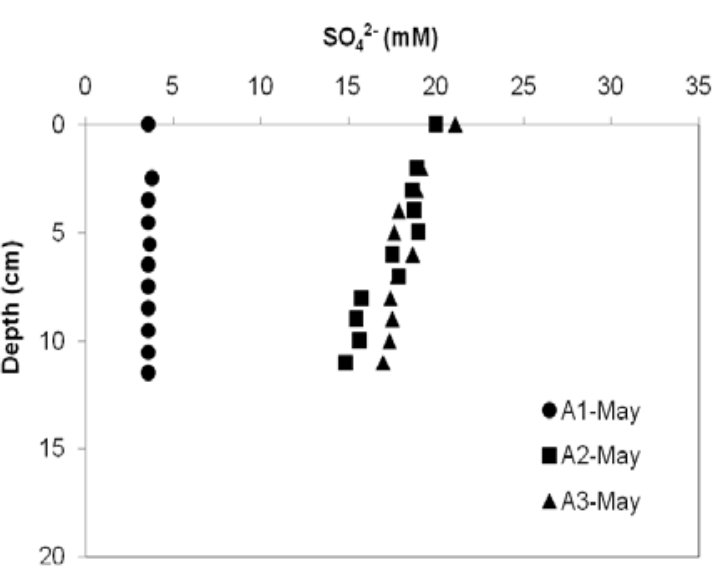

I

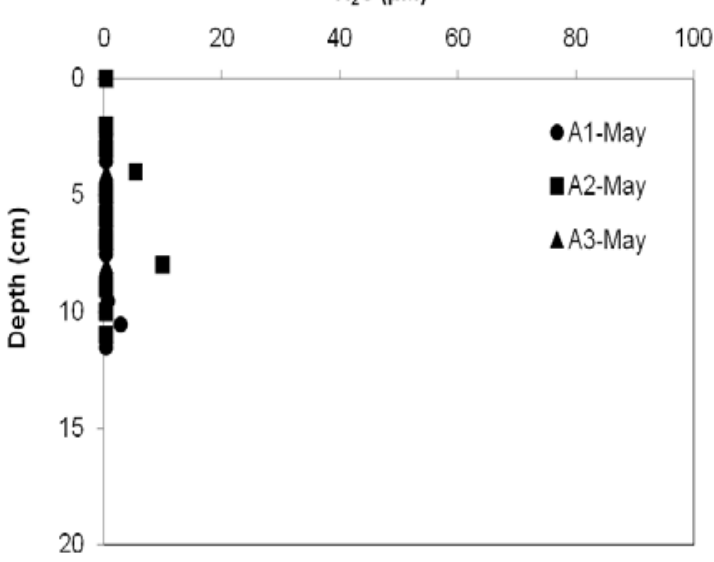

$\mathbf{n}$

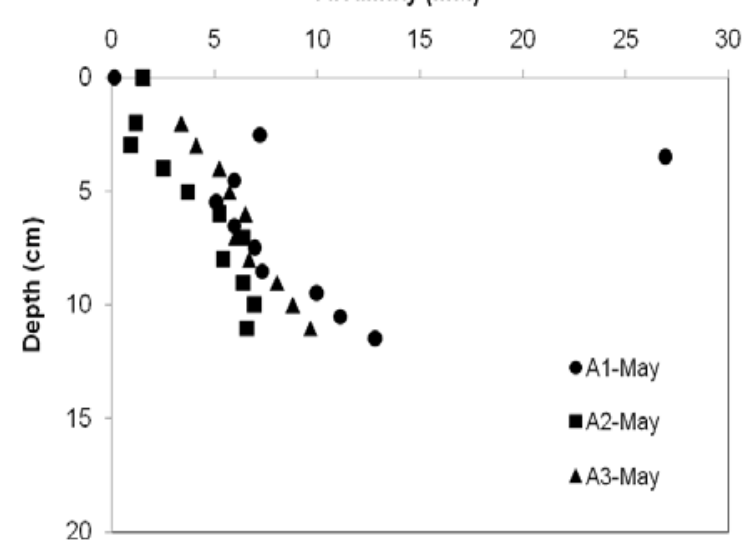

Fig.8 Nitrate profiles over depth (a, b), ammonium profiles over depth (c, d), iron profiles over depth (e, f), manganese profiles over depth (g, h), sulfate profiles over depth (i, j), sulfide profiles over depth (k, l), alcalinity profiles over depth (m, n). Left and right panels represent the Elorn and Aulne Estuary, respectively, in May 

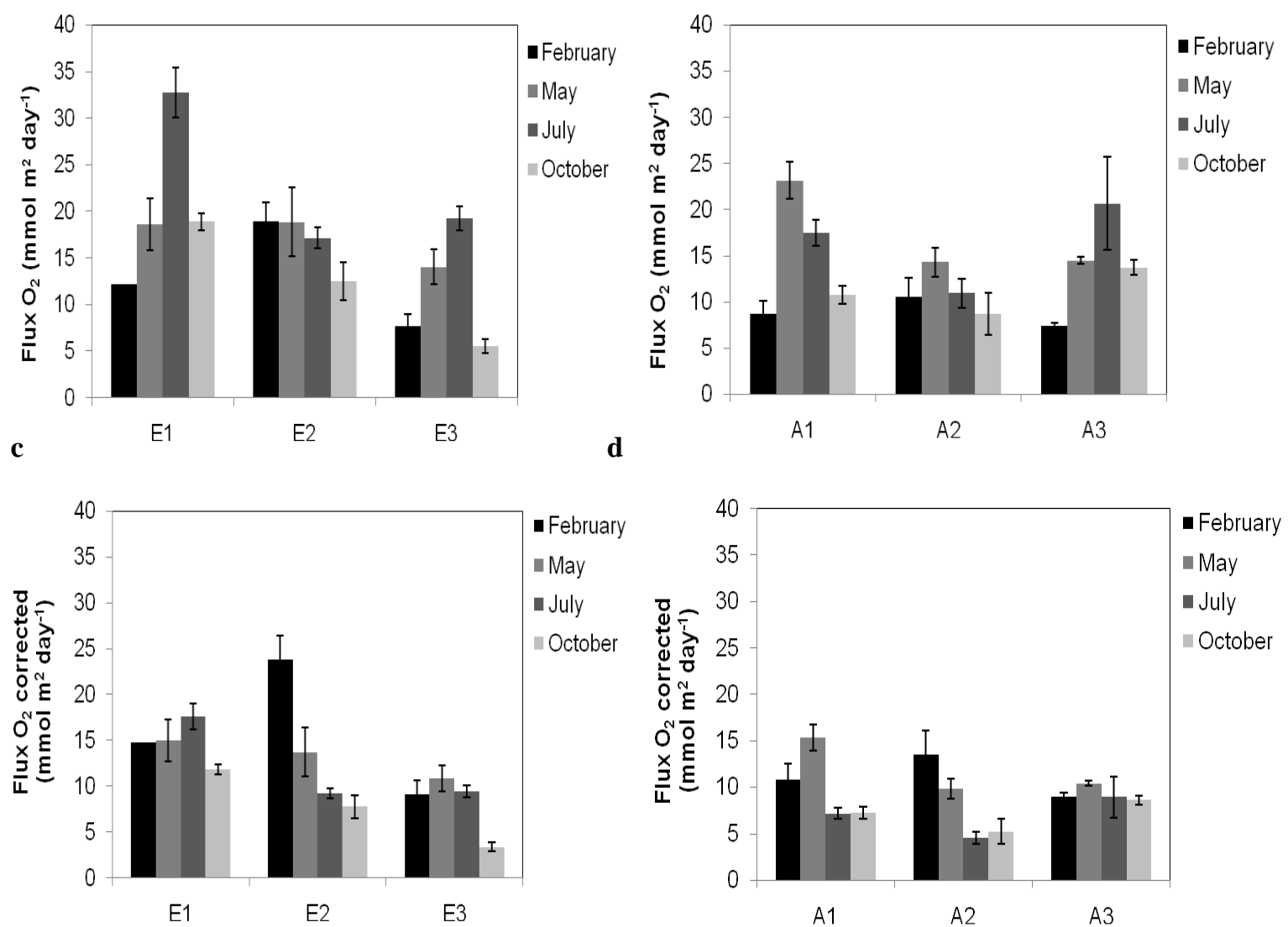

Fig.9 Diffusive oxygen fluxes at February, May, July and October (a, b). Diffusive oxygen fluxes recalculated for a temperature of $10^{\circ} \mathrm{C}$ corresponding to each season February, May, July and October (c, d). Left and right panels represent the Elorn and Aulne Estuary, respectively 

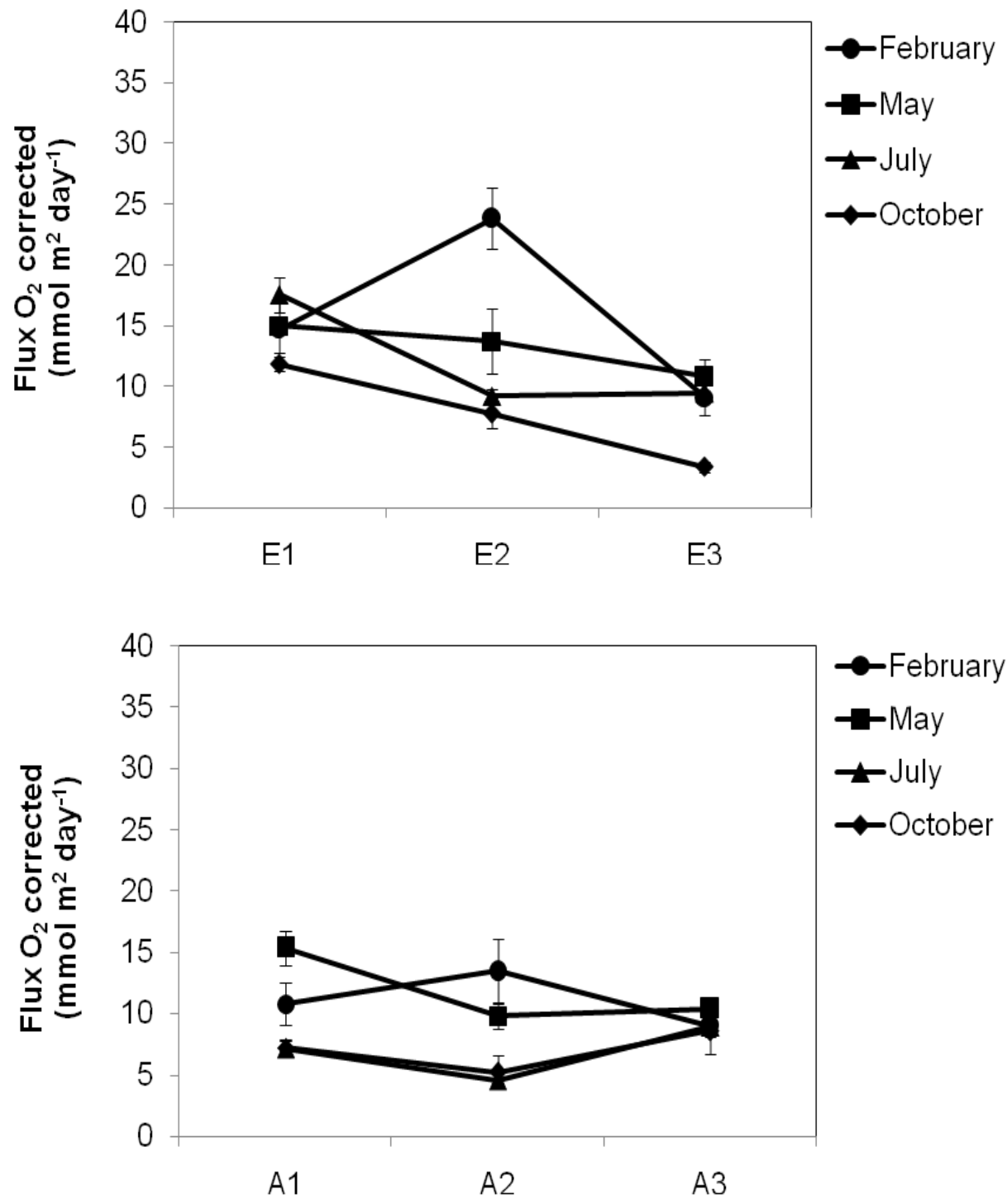

Fig.10: T-corrected diffusive oxygen fluxes $\left(a t 10^{\circ} \mathrm{C}\right)$ along the Elorn and Aulne estuaries at the four different seasons 


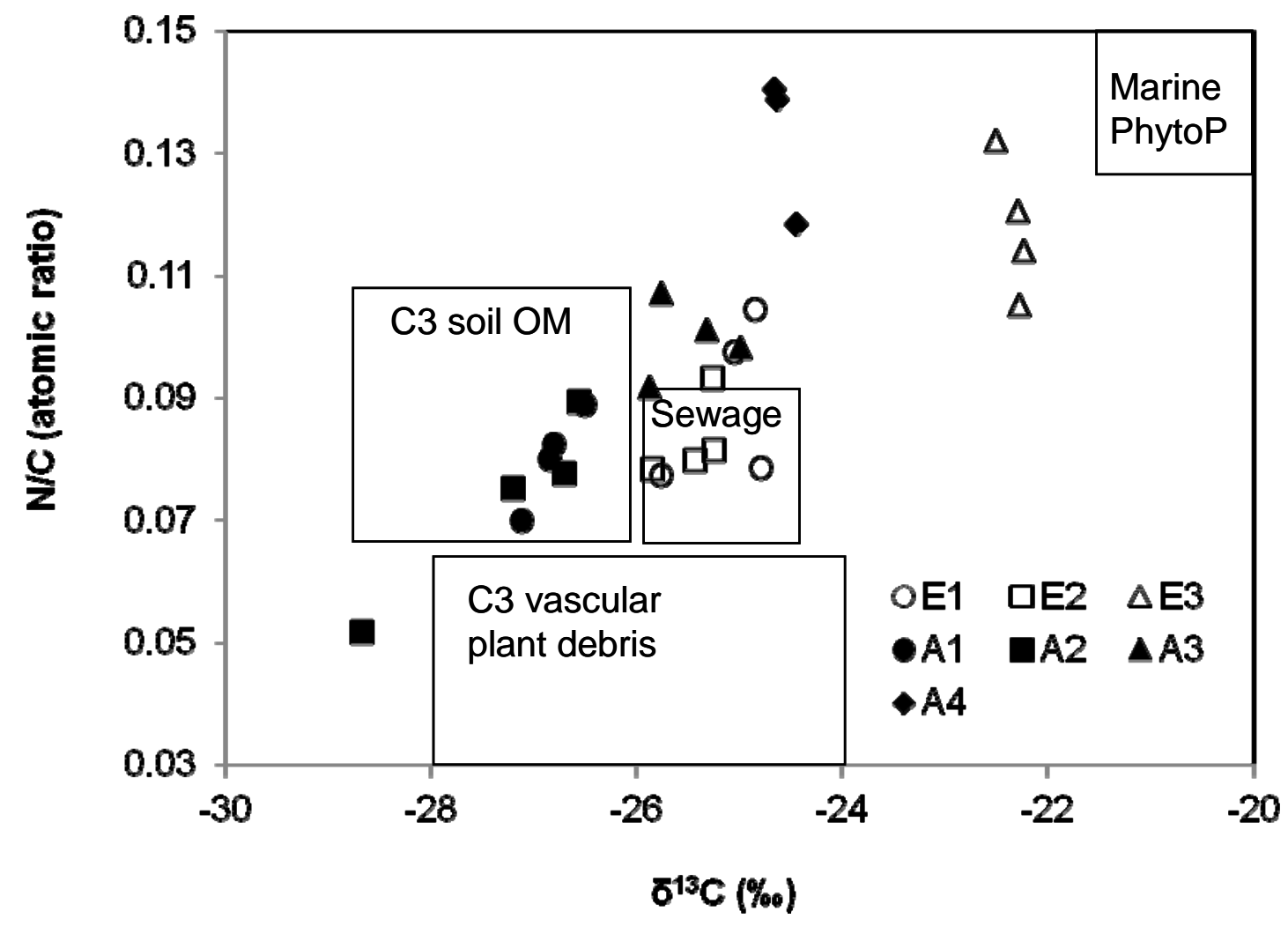

Fig.11 Stable isotopic composition of organic carbon $\left(\delta^{13} \mathrm{C}\right)$ versus atomic nitrogen:carbon ratios (N/C) measured in the top sediment layer for Elorn and Aulne Estuary respectively, on level 0-0.5 cm in February cruise and on 50/50 mix of level 0-0.5 and 2-3 cm in May, July and October. The compositions of four possible organic carbon sources (terrigenous C3 vascular plant, C3 soil OM, sewage and marine phytoplankton) are also plotted to illustrate the relative influence of each source. Station A4 is located in the outer estuary downstream of A3, with larger salinity waters 